تี Max-Planck-Institut

für ausländisches und internationales Privatrecht

\title{
Rabels Zeitschrift
}

für ausländisches und internationales Privatrecht

\section{The Rabel Journal}

of Comparative and International Private Law

Stand und Perspektiven des Einheitsrechts

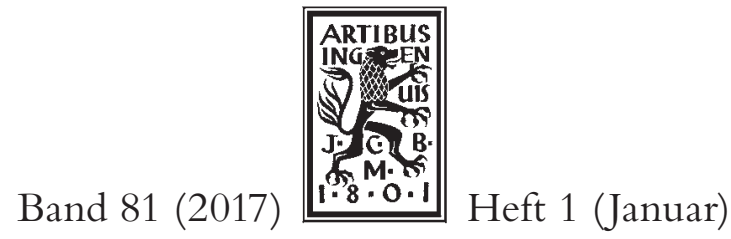

Digitaler Sonderdruck des Autors mit Genehmigung des Verlages 


\title{
Rabels Zeitschrift für ausländisches und internationales Privatrecht

\author{
The Rabel Journal \\ of Comparative and International Private Law
}

\author{
Herausgegeben in Gemeinschaft mit \\ Ulrich Drobnig, Bernhard Großfeld, Klaus J. Hopt, Hein Kötz, \\ Ernst-Joachim Mestmäcker, Wernhard Möschel \\ von
}

Jürgen Basedow, Holger Fleischer und Reinhard Zimmermann

Direktoren am Institut

Redaktion: Max-Planck-Institut für ausländisches und internationales Privatrecht, Mittelweg 187, D-20148 Hamburg

Telefon 040/41900-234 - Telefax 040/41900-288

Redaktionsausschuss: Christian Eckl, Jens Kleinschmidt, Christoph Kumpan,

Klaus Ulrich Schmolke, Kurt Siehr, Wolfgang Wurmnest

Redaktionsassistenz: Sophie Knebel, Anke Schild

Manuskripte: rabelsz@mpipriv.de

\begin{abstract}
All Rabel Journal articles are subject to peer review by at least two experts familiar with their subject matter. For more information on the submission procedure and for the style sheet in English and German please visit <www.mohr.de/rabelsz>.
\end{abstract}

Die Annahme zur Veröffentlichung erfolgt schriftlich und unter dem Vorbehalt, dass das Manuskript nicht anderweitig zur Veröffentlichung angeboten wurde. Mit der Annahme zur Veröffentlichung überträgt der Autor dem Verlag das ausschließliche Verlagsrecht. Das Verlagsrecht endet mit dem Ablauf der gesetzlichen Urheberschutzfrist.

Der Autor behält das Recht, ein Jahr nach der Veröffentlichung einem anderen Verlag eine einfache Abdruckgenehmigung zu erteilen.

Bestandteil des Verlagsrechts ist das Recht, den Beitrag fotomechanisch zu vervielfältigen und zu verbreiten, und das Recht, die Daten des Beitrags zu speichern und aufDatenträger oder im Online-Verfahren zu verbreiten.

Erscheinungsart: Bandweise, pro Jahr ein Band zu 4 Heften mit je etwa 225 Seiten. Empfohlener Verkaufspreis pro Band: $€ 319$,- für Institutionen einschließlich eines IP-gesteuerten, elektronischen Zugangs mit Hyperlinks. Der Zugang gilt für einen Standort einer mittelgroßen Institution mit bis zu 40.000 Nutzern (FTE). Als mehrere Standorte gelten Institutionen dann, wenn die Einrichtung in unterschiedlichen Städten liegen. Multi-Sites und größere Institutionen bitten wir um Einholung eines Preisangebots direkt beim Verlag. Kontakt: elke.brixner@mohr.de. Abonnement für Privatpersonen: $€ 164,-$, einschließlich eines elektronischen Zugangs über Benutzername und Passwort. Einzelheftpreis: $€$ 92,-, jeweils zuzüglich Versandkosten. Abbestellungen sind nur zum Jahresende für das folgende Jahr möglich. Die Abbestellung muss bis spätestens 30 . November erfolgen. Eine Einbanddecke ist zum Preis von $€ 20,-$ lieferbar. Verlag: Mohr Siebeck GmbH \& Co. KG, Postfach 2040, 72010 Tübingen. Vertrieb: über den Buchhandel.

(C) 2016 Mohr Siebeck GmbH \& Co. KG, Tübingen. - Die Zeitschrift und alle in ihr enthaltenen einzelnen Beiträge und Abbildungen sind urheberrechtlich geschützt. Jede Verwertung außerhalb der engen Grenzen des Urheberrechtsgesetzes ist ohne Zustimmung des Verlags unzulässig und strafbar. Das gilt insbesondere für Vervielfältigungen, Übersetzungen, Mikroverfilmungen und die Einspeicherung und Verarbeitung in elektronischen Systemen.

Satz und Druck: Gulde-Druck, Tübingen.

ISSN 0033-7250

Digitaler Sonderdruck des Autors mit Genehmigung des Verlages 


\title{
Inhalt dieses Heftes
}

\author{
Schwerpunkte
}

„Stand und Perspektiven des Einheitsrechts“ . . . . . . . . . . 1-193

BASEDOW, JÜRgEN, Internationales Einheitsprivatrecht im Zeitalter der Globalisierung . . . . . . . . . . . . .

Summary: The International Unification of Private Law in the Era of Globalization . . . . . . . . . . . . . . .

Schroeter, Ulrich G., Gegenwart und Zukunft des Einheitskauf-

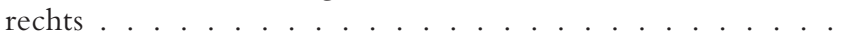

Summary: Present and Future of Uniform Sales Law . . . . .

Huber, Stefan, Transnationales Kreditsicherungsrecht . . . . . 77-116 Summary: Secured Transactions Law: A Transnational Perspective

Maurer, Andreas, Einheitsrecht im internationalen Warentransport . . . . . . . . . . . . . . . 117-157

Summary: Uniform Law in the International Transport of Goods . . . . . . . . . . . . . . . . .

Peukert, Alexander, Vereinheitlichung des Immaterialgüterrechts: Strukturen, Akteure, Zwecke . . . . . . . . . . . . . Summary: Unification of Intellectual Property Law: Structures, Actors and Aims . . . . . . . . . . . . . . . . . . . .

\section{Literatur}

\section{Buchbesprechungen}

Oppong, Richard Frimpong: Private International Law in Commonwealth Africa. Cambridge 2013 (Ulrich SpellendergG) . . . . 194-198

Wyen, Jan-Henning: Rechtswahlfreiheit im europäischen Insolvenzrecht. Eine Untersuchung zum forum shopping unter der EuInsVO unter besonderer Berücksichtigung von Effizienzgesichtspunkten. Tübingen 2014 (Axel Flessner) . . . . . . . 
Kühn, Anna-Lisa: Die gestörte Gesamtschuld im Internationalen Privatrecht. Am Beispiel einer Spaltung des Mehrpersonenverhältnisses zwischen deutschem und englischem Recht. Tübingen 2014 (Dieter Martiny) . . . . . . . . . . . . . . . . . . $201-203$

Bareiß, Andreas: Pflichtenkollisionen im transnationalen Beweisverkehr. Offenbarungspflichten im Zivilprozessrecht der USA und Offenbarungsverbote nach deutschem und europäischem Recht. Tübingen 2014 (Dagmar Coester-Waltjen) . . . . . . . . .

de Miguel Asensio, Pedro A.: Derecho Privado de Internet. 5a Edición. Cizur Menor 2015 (Laura Carballo Piñeiro) . . . . . . . . $212-216$

Private Macht. Hrsg. von Florian Möslein. Tübingen 2016 (VolkeR EMmerich) . . . . . . . . . . . . . . . . . . . . . . . . . 216-219

Bergmann, Andreas: Die Rechtsfolgen des ungerechten Vertrages. Die Grundlegung einer Lehre der materiellen Vertragsgerechtigkeit. Tübingen 2014 (Aleksander Grebieniow) . . . . . . . . . .

Vormundschaft in Europa. Hrsg. von Anatol Dutta, Dieter Schwab, Dieter Henrich, Peter Gottwald, Martin Löhnig. Bielefeld 2015 (Andreas Botthof). . . . . . . . . . . . . . . . . .

Erbrecht in der VR China. Die aktuelle Entwicklung im Rahmen des Aufbaus der Privatrechtsordnung. Hrsg. von Christina EberlBorges und Wang Qiang. Frankfurt am Main u.a. 2015 (Anatol DutTA) . . . . . . . . . . . . . . . . . . .

Klumpp, Marianne: Schiedsgerichtsbarkeit und Ständiges Revisionsgericht des Mercosur. Integrationsförderung durch zwischenstaatliche Streitbeilegung und Rechtsprechung im Mercosur. Heidelberg u.a. 2013 (Jürgen Samtleben) . . . . . . . . .

Fikentscher, Wolfgang: Law and Anthropology. 2nd edition. BadenBaden u.a. 2016 (HANs-GeOrg EBERT)

II. Eingegangene Bücher . . . . . . . . . . . . . . . . 243-246

Mitarbeiter dieses Heftes. . . . . . . . . . . . . . . 
Digitaler Sonderdruck des Autors mit Genehmigung des Verlages 


\title{
Gegenwart und Zukunft des Einheitskaufrechts
}

\author{
Von Ulrich G. Schroeter, Mannheim
}

Inhaltsübersicht

I. Einführung . . . . . . . . . . . . . . . . 33

II. Entwicklung. . . . . . . . . . . . . . . . . . . . . . . 34

1. Erste Vorarbeiten . . . . . . . . . . . . . . . . . . 35

2. Die Haager Einheitlichen Kaufgesetze (1964) . . . . . . . . . . 36

3. Das UN-Kaufrecht (1980) . . . . . . . . . . . . . . 37

III. Akzeptanz durch Staaten . . . . . . . . . . . . . . . . . . . . 38

1. Ratifikationsentwicklung und -stand ............ 39

2. Tendenz zur Rücknahme von Vorbehaltserklärungen . . . . . . . 40

3. UN-Kaufrecht im Rechtsunterricht . . . . . . . . . . . 41

IV. Akzeptanz (oder Ausschluss) durch private Parteien . . . . . . . . . 42

1. „Opt out"-Modell des Einheitskaufrechts . . . . . . . . . . . . . 42

2. Einigung beider Vertragsparteien als Ausschlussvoraussetzung . . . . 43

3. Empirie und Folgerungen . . . . . . . . . . . . . . . . 44

V. Auslegung durch Gerichte und Schiedsgerichte . . . . . . . . . . . . 45

1. Zahlen . . . . . . . . . . . . . . . 45

2. Vorgaben des Art. 7(1) CISG und ihre praktische Umsetzung . . . . 46

a) Steuerung der Interpretation durch Auslegungsziele . . . . . . . 47

(1) Die Auslegungsziele im Überblick . . . . . . . . . . . . . 48

(2) Die Beachtung der Auslegungsziele in der gerichtlichen Praxis. 51

b) Institutionelle Rahmenbedingungen der Auslegung . . . . . . . 55

(1) Fehlen eines Obergerichts mit zentraler Auslegungszuständigkeit . . . . . . . . . . . 56

(2) Kooperation zwischen vertragsstaatlichen Gerichten . . . . . 57

(3) Unterstützende Maßnahmen UNCITRALs . . . . . . . 58

(4) Die Mittlerrolle der Wissenschaft in grenzüberschreitender
Kooperation. . . . . . . . . . . . . 59

c) Verfahrensrechtliche Umsetzung der Vorgaben des Art. 7(1) CISG 60

3. Abgrenzung des Anwendungsbereiches des Einheitskaufrechts . . . . 63

4. Lückenfüllung . . . . . . . . . . . . . . . . . 64

5. Einheitskaufrecht in der Schiedsgerichtsbarkeit . . . . . . . . 66

VI. Modellfunktion des UN-Kaufrechts . . . . . . . . . . . . . . . 67

1. Modell für anderes Einheitsrecht . . . . . . . . . . . . . 67

2. Modell für nationale und regionale Rechtsreformen . . . . . . . . 68

RabelsZ 81, 32-76 - DOI: 10.1628/003372516X14817241954953

ISSN 0033-7250 - (C) 2017 Mohr Siebeck

Digitaler Sonderdruck des Autors mit Genehmigung des Verlages 
VII. Weiterentwicklung und Ergänzung des UN-Kaufrechts . . . . . . . . 69

1. Weiterentwicklung . . . . . . . . . . . . . . . . 69

a) Revision des Übereinkommenstextes? . . . . . . . . . . . . . 69

b) Primat judikativer Weiterentwicklung . . . . . . . . . . . . . 70

2. Ergänzung durch weiteres Einheitsrecht . . . . . . . . . . . . . . 70

VIII. Koordination und Konfliktauflösung innerhalb des kaufrechtsbezogenen Einheitsrechts . . . . . . . . . . . . . . 71

1. Internationale Einheitsrechtsakte . . . . . . . . . . 71

2. UN-Kaufrecht und regionale Rechtsvereinheitlichung (insbesondere in der EU) . . . . . . . . . . . . . . . . . . . 73

IX. Zusammenfassung . . . . . . . . . . . . . . . . . . 74

Summary: Present and Future of Uniform Sales Law . . . . . . . . 76

\section{Einführung}

Unter den Teilgebieten des Einheitsprivatrechts nimmt das Einheitskaufrecht aus mehreren Gründen eine besondere Stellung ein. So stellt es erstens, obgleich nicht zu den frühesten Gegenständen der internationalen Privatrechtsvereinheitlichung ${ }^{1}$ zählend, mit dem UN-Kaufrecht ${ }^{2}$ eines derjenigen einheitsrechtlichen Übereinkommen, die weltweit vergleichsweise große Verbreitung gefunden haben; dieses ist heute in über 80 Staaten auf allen fünf Kontinenten geltendes Recht. ${ }^{3}$ Zweitens betrifft das Einheitskaufrecht in Gestalt des Kaufvertrags den wichtigsten Vertragstyp der internationalen Wirtschaft, ${ }^{4}$ denn Kaufverträge fungieren typischerweise als Hauptverträge grenzüberschreitender Austauschbeziehungen, ohne die zahlreiche weitere Verträge (etwa Transport-, Akkreditiv- und Transportversicherungsverträge) gar nicht oder nur deutlich seltener geschlossen würden. Hinzu kommt eine dogmatische Leitfunktion des Kaufvertrages, weil das allgemeine Vertragsrecht in den meisten nationalen Rechtsordnungen mit Blick auf den Kaufvertrag entwickelt wurde ${ }^{5}$ und dessen rechtliche Ordnung zudem auch auf benachbarte Rechtsmaterien ausstrahlt.

Drittens ist für (Waren-)Kaufverträge bezeichnend, dass sie von Wirtschaftsakteuren jedweder Größe auch über gelegentlich geringe Vertragswerte und daher vielfach ohne Rechtsberatung abgeschlossen werden; es handelt sich mit anderen Worten auch im grenzüberschreitenden Verkehr um Alltagsverträge. Dies hat wiederum zur Folge, dass das Einheitskaufrecht in der Praxis regelmäßig von Rechtsanwendern ohne spezielle Vor-

${ }^{1} \mathrm{Zu}$ diesen Jürgen Basedow, Internationales Einheitsprivatrecht im Zeitalter der Globalisierung, RabelsZ 81 (2017) 1-31 (in diesem Heft).

${ }^{2}$ United Nations Convention on Contracts for the International Sale of Goods (CISG), Wien 11.4.1980, 1489 United Nations Treaty Series (UNTS) 58.

${ }^{3}$ Näher unter III. 1.

${ }^{4}$ Fritz Enderlein/Dietrich Maskow/Heinz Strohbach, Internationales Kaufrecht (1991) 29.

5 Ernst Rabel, Das Recht des Warenkaufs, Bd. I (Neudruck 1964) 19.

\section{Digitaler Sonderdruck des Autors mit Genehmigung des Verlages}


kenntnisse angewandt wird und sich auch insoweit bewähren muss. Darin unterscheidet es sich etwa vom Übereinkommen von Kapstadt über Sicherungsrechte an beweglicher Ausrüstung wie Luftfahrzeugen, Satelliten oder Weltraumstationen, ${ }^{6}$ mit dem infolge seines speziellen Gegenstandes in der Regel nur spezialisierte Juristen und Unternehmen befasst sind und das sich damit an einen ganz anderen Adressatenkreis richtet. Das Einheitskaufrecht, dessen Entwicklung zunächst von akademischer Seite initiiert und durch die wissenschaftliche Neugierde einer Reihe glänzender Rechtsvergleicher vorangetrieben worden war, ${ }^{7}$ ist demgegenüber heute zum Bestandteil des rechtlichen Alltagsgeschäfts der meisten Länder geworden, in denen internationaler Handel getrieben wird.

Die folgende Abhandlung erörtert nach einem kurzen Blick auf die historische Entwicklung des Einheitskaufrechts (II.) zunächst dessen Akzeptanz durch Staaten (III.) und durch private Parteien in der Gegenwart (IV.), bevor sie sich in Gestalt der Auslegung des Einheitskaufrechts durch Gerichte und Schiedsgerichte sowie der diversen damit verbundenen Fragestellungen (V.) den Kernfragen zuwendet, welche die Zukunft dieses Einheitsrechtsgebiets bestimmen werden. Es folgt eine Behandlung der Modellfunktion des UN-Kaufrechts (VI.), seiner künftigen Weiterentwicklung und Ergänzung (VII.) sowie der zunehmend erforderlichen Koordination und Konfliktlösung innerhalb des kaufrechtsbezogenen Einheitsrechts (VIII.), bevor die Abhandlung mit einer Zusammenfassung (IX.) schließt.

\section{Entwicklung}

Ein knapper Überblick über die entstehungsgeschichtliche Entwicklung des modernen Einheitskaufrechts bildet die Grundlage für die Erörterung von dessen Status quo und Zukunft. Die bereits angesprochene, zentrale Rolle des grenzüberschreitenden Kaufvertrags als Rechtsvereinheitlichungsgegenstand spiegelt sich dabei in dem Umstand wider, dass sämtliche der drei internationalen Rechtsvereinheitlichungsorganisationen mit horizontaler Zuständigkeit (UNIDROIT, die Haager Konferenz für Internationales Privatrecht und UNCITRAL $)^{8}$ sich im Laufe der Zeit einheitskaufrechtlichen Projekten gewidmet haben.

${ }^{6}$ Convention on International Interests in Mobile Equipment, Kapstadt 16.11.2001, 2307 UNTS 285, mit Protocol to the Convention on International Interests in Mobile Equipment on Matters Specific to Aircraft Equipment, Kapstadt 16.11.2001, 2367 UNTS 556, und Protocol to the Convention on International Interests in Mobile Equipment on Matters Specific to Space Assets, Berlin 9.3.2012.

7 Hein Kötz, Rechtsvereinheitlichung - Nutzen, Kosten, Methoden, Ziele, RabelsZ 50 (1986) $1,9$.

${ }^{8}$ Siehe zu diesen schon Basedow, RabelsZ 81 (2017) 1-31 (in diesem Heft); Jan Kropholler, Internationales Einheitsrecht (1975) $43 \mathrm{ff}$.

Schwerpunkt: Stand und Perspektiven des Einheitsrechts

\section{Digitaler Sonderdruck des Autors mit Genehmigung des Verlages}




\section{Erste Vorarbeiten}

Die Entwicklung des geschriebenen Einheitsrechts für internationale Kaufverträge beginnt im Jahr 1928, als kurz nacheinander zwei separate Vereinheitlichungsprojekte in Gang gesetzt wurden: Im Januar beschloss die von der niederländischen Regierung einberufene Sechste Haager Konferenz für Internationales Privatrecht, Möglichkeiten zur Vereinheitlichung des Kollisionsrechts des Kaufes zu prüfen. ${ }^{9}$ Schon bald nach Gründung und Einweihung des Instituts für die Vereinheitlichung des Privatrechts (UNIDROIT) in Rom im Mai 1928 schlug sodann Ernst Rabel dem Präsidenten des Instituts, Vittorio Scialoja, die Vereinheitlichung des materiellen Rechts des internationalen Warenkaufs als Projekt vor. ${ }^{10}$

In der Folgezeit wurden sowohl zum kollisionsrechtlichen als auch zum materiellen Einheitskaufrecht erste Entwürfe erarbeitet, ${ }^{11}$ bevor die diesbezüglichen Bemühungen durch den Zweiten Weltkrieg unterbrochen wurden. Ihre Wiederaufnahme trug zunächst im Bereich des Kollisionsrechts Früchte und führte 1951 zur Fertigstellung des Haager Übereinkommens betreffend das auf internationale Kaufverträge über bewegliche körperliche Sachen anzuwendende Recht, das am 15. Juni 1955 von den ersten Staaten gezeichnet wurde und daher üblicherweise unter diesem Datum geführt wird. ${ }^{12}$ Es gilt bis heute in sieben westeuropäischen Staaten. ${ }^{13}$

Drei Jahre später nahm die Haager Konferenz noch zwei weitere ,Satelliten-Abkommen"14 an, die in Gestalt des auf den Eigentumsübergang anwendbaren Rechts ${ }^{15}$ und der Zuständigkeit des vertraglich vereinbarten Gerichts ${ }^{16}$ weitere, allerdings deutlich enger gefasste Rechtsfragen internationaler Mobiliarkäufe zu vereinheitlichen versuchten. Beide traten jedoch nie in Kraft.

\footnotetext{
9 Conférence de La Haye de Droit International Privé, Documents relatifs à la Sixième Session tenue du 5 au 28 Janvier 1928 (1928) 18, 33 ff.

${ }^{10}$ Ernst Rabel, Mitteilungen: Internationales Institut für die Vereinheitlichung des Privatrechts in Rom, RabelsZ 3 (1929) 402, $405 \mathrm{f}$.

${ }^{11} \mathrm{Im}$ materiellen Einheitskaufrecht ist insbesondere der Entwurf eines einheitlichen Kaufgesetzes von 1935 zu nennen; siehe zu diesem Ernst Rabel, Der Entwurf eines einheitlichen Kaufgesetzes, RabelsZ 9 (1935) $1 \mathrm{ff}$.

12 Convention du 15 juin 1955 sur la loi applicable aux ventes à caractère international d'objets mobiliers corporels, 510 UNTS 147.

${ }_{13}$ Dänemark, Finnland, Frankreich, Italien, Norwegen, Schweden, Schweiz. Belgien kündigte das Übereinkommen im Jahre 1999.

${ }^{14}$ So Georg Petersen, Die 8. Haager Konferenz, RabelsZ 24 (1959) 1, 21.

${ }^{15}$ Convention du 15 avril 1958 sur la loi applicable au transfert de la propriété en cas de vente à caractère international d'objets mobiliers corporels, Recueil des Conventions de La Haye (1966) 16

16 Convention du 15 avril 1958 sur la compétence du for contractuel en cas de vente à caractère international d'objets mobiliers corporels, Recueil des Conventions de La Haye (1966) 20.
} 


\section{Die Haager Einheitlichen Kaufgesetze (1964)}

Die Bemühungen UNIDROITs zur Schaffung eines materiellen Einheitskaufrechts resultierten schließlich in den beiden Haager Einheitlichen Kaufgesetzen, von denen eines das Recht des Abschlusses internationaler Kaufverträge und das andere das materielle Kaufrecht zum Gegenstand hatte. Beide Einheitsgesetze fanden sich als lois uniformes im Anhang zweier Übereinkommen, die im Jahre 1964 auf einer diplomatischen Konferenz in Den Haag verabschiedet und zur Ratifikation freigegeben wurden. ${ }^{17}$ (Dass die diplomatische Konferenz im Haag tagte, ging auf eine diesbezügliche Einladung der niederländischen Regierung zurück; mit der Haager Konferenz für IPR, die einige Jahre zuvor infolge ihres mittlerweile ständigen Charakters formell als internationale Organisation konstituiert worden war, ${ }^{18}$ hatten die Haager Kaufgesetze dagegen nichts zu tun.)

Die Einheitlichen Kaufgesetze wurden in der Folgezeit von insgesamt neun vor allem westeuropäischen Staaten ratifiziert ${ }^{19}$ und erlangten in einigen von ihnen - namentlich in Deutschland - durchaus praktische Bedeutung. ${ }^{20}$ Anders war die Lage insbesondere im Vereinigten Königreich, das die Haager Kaufgesetze in Zusammenhang mit seinem Beitritt zur E(W)G zwar ebenfalls in Kraft gesetzt, ${ }^{21}$ dabei jedoch einen (zulässigen) Vorbehalt erklärt hatte, wonach diese nur bei ihrer Wahl durch die Kaufvertragsparteien anzuwenden waren. Als Folge blieben die Einheitlichen Kaufgesetze in Großbritannien, wo sie bis heute unverändert gelten, vollkommen bedeutungslos ${ }^{22}$ - tatsächlich haben die dortigen Gerichte keinen einzigen Fall entschieden, in dem das Einheitskaufrecht von 1964 zur Anwendung kam. ${ }^{23}$

Außerhalb Westeuropas fanden die Haager Kaufgesetze demgegenüber von vornherein fast keine Annahme. Der Hauptgrund dafür, dass sich weder

17 Convention relating to a Uniform Law on the International Sale of Goods und Convention relating to a Uniform Law on the Formation of Contracts for the International Sale of Goods, beide Den Haag 1.7.1964.

${ }^{18} \mathrm{Vgl}$. Präambel der Satzung der Haager Konferenz für Internationales Privatrecht (in Kraft getreten am 15. Juli 1955, geändert am 30. Juni 2005), die den ,ständigen Charakter“ der Haager Konferenz betont.

${ }^{19}$ Belgien, Bundesrepublik Deutschland, Gambia, Israel, Luxemburg, Niederlande, San Marino, Vereinigtes Königreich.

20 Peter Schlechtriem, Einheitliches UN-Kaufrecht (1981) 2.

${ }^{21} \mathrm{Vgl}$. Jacob S. Ziegel, The Future of the International Sales Convention from a Common Law Perspective, N.Z. Bus. L.Q. 6 (2000) 336, 337 Fn. 4: ,The UK's adherence was inspired by its joining the Common Market and was apparently regarded by the British government of the day as a gesture of goodwill towards its new economic and political partners.“

${ }^{22}$ Michael G. Bridge, The International Sale of Goods³ (2013) Rn. 10.08: „For all practical purposes, this rendered the two Conventions a dead letter as far as the United Kingdom was concerned."

${ }^{23}$ Eine obiter-Bezugnahme findet sich in Butler Machine Tool Co v Ex-Cell-o Corp [1979] 1 All ER 965.

Schwerpunkt: Stand und Perspektiven des Einheitsrechts

\section{Digitaler Sonderdruck des Autors mit Genehmigung des Verlages}


sonstige common law-Staaten noch Staaten des sozialistischen Ostblocks oder Entwicklungsländer zur Ratifikation entschließen konnten, lag allerdings nicht im Inhalt ihrer materiellen Vorschriften (die später überwiegend in das heute global akzeptierte UN-Kaufrecht ${ }^{24}$ übernommen wurden), sondern im ausgeprägt westeuropäischen Fokus ihrer Entstehungsgeschichte: Auf der Haager Konferenz von 1964 waren 28 Staaten nahezu ausschließlich aus dem westlichen Europa ${ }^{25}$ vertreten, sodass sich andere Staaten verständlicherweise nicht repräsentiert fühlten. ${ }^{26}$ Infolge dieses Mankos erwiesen sich die Haager Einheitlichen Kaufgesetze als von Anfang an untauglicher Versuch, ein weltweit akzeptables Einheitskaufrecht zu schaffen.

\section{Das UN-Kaufrecht (1980)}

Hierauf reagierte mit der United Nations Commission on International Trade Law (UNCITRAL) eine 1966 neu gegründete Rechtsvereinheitlichungsorganisation, die als eines ihrer ersten Projekte die Überarbeitung der (zu diesem Zeitpunkt noch gar nicht in Kraft getretenen) Haager Kaufgesetze ins Auge fasste, mit dem erklärten Ziel, so ihre Annehmbarkeit für Staaten mit unterschiedlichen Rechts-, Sozial- und Wirtschaftssystemen zu erhöhen. ${ }^{27}$ Im Rückblick erscheint dies deshalb bemerkenswert, weil UNCITRAL sich damit der Reform eines Einheitsrechts annahm, das im Rahmen einer anderen Organisation (nämlich UNIDROIT) geschaffen worden war. $^{28}$

In der Sache verliefen die Überarbeitungsbemühungen erfolgreich: Die Arbeitsgruppen innerhalb UNCITRALs, in denen Staaten aller Erdteile vertreten waren, übernahmen die meisten Bestimmungen der Haager Kaufgesetze, ${ }^{29}$ gestalteten die Anwendungsvoraussetzungen aber neu (und einfacher) und führten die beiden separaten Gesetze schließlich in einem Übereinkommen zusammen. Soweit einzelne kaufrechtliche Vorschriften

${ }^{24}$ Dazu sogleich unter II.3.

${ }^{25}$ Hinzu kamen aus Osteuropa Bulgarien, Jugoslawien und Ungarn sowie aus den übrigen Regionen der Welt Israel, Kolumbien, Japan, die Türkei, die USA und die Vereinigte Arabische Republik. Damit stammten 19 der 28 durch Delegationen vertretenen Staaten aus Westeuropa.

${ }^{26}$ So zur Perspektive der Entwicklungsländer S.K. Date-Bah, The Convention on the International Sale of Goods from the Perspective of the Developing Countries, in: La vendita internazionale (1981) 23, 26; zur Perspektive der damaligen sozialistischen Staaten Enderlein/ Maskow/Strohbach, Int. Kaufrecht (Fn. 4) 24.

${ }^{27}$ UNCITRAL Yearbook I (1968-1970) 78f., $99 \mathrm{f}$.

${ }^{28}$ Eric E. Bergsten, Thirty-five years of the United Nations Convention on Contracts for the International Sale of Goods: Expectations and Deliveries, in: Thirty-five Years of Uniform Sales Law: Trends and Perspectives, hrsg. von UNCITRAL (2015) 7, 11: „This was a somewhat problematic decision, given that the uniform laws had been prepared by Unidroit."

${ }^{29}$ Peter Schlechtriem/Ulrich G. Schroeter, Internationales UN-Kaufrecht ${ }^{5}$ (2013) Rn. 5.

\section{Digitaler Sonderdruck des Autors mit Genehmigung des Verlages}


inhaltlich geändert wurden, schlug sich darin vor allem ein stärkerer Einfluss des common law nieder. Nachdem UNCITRAL zwischenzeitlich schon ein Übereinkommen über die Verjährung beim internationalen Warenkauf $^{30}$ verabschiedet hatte, wurde im März/April 1980 eine Diplomatische Konferenz in der Wiener Hofburg einberufen, um über den endgültigen Text des neuen Einheitskaufrechts zu verhandeln. Mit Delegationen aus 62 Staaten aller Erdteile und politischen Systeme sowie acht internationalen Organisationen als Beobachter (darunter auch die $\mathrm{E}(\mathrm{W}) \mathrm{G}$ ) war dabei eine deutlich breitere Repräsentanz gewährleistet als 16 Jahre zuvor in Den Haag. Am 11. April 1980 wurde der erarbeitete Text des UN-Kaufrechts ${ }^{31}$ in Wien ohne Gegenstimmen, aber mit einzelnen Enthaltungen verabschiedet.

\section{Akzeptanz durch Staaten}

Die Einigung auf einen Übereinkommenstext ist ein notwendiger, aber allein noch nicht ausreichender Schritt, um internationalem Einheitsrecht zu rechtlicher Geltung zu verhelfen: Es bedarf zusätzlich der Ratifikation des oder des Beitritts zu dem Übereinkommen durch eine hinreichende Anzahl von Staaten, worin sich deren Akzeptanz des Einheitsrechts formell manifestiert. Unmittelbar nach Abschluss der Wiener Konferenz von 1980 war dies für das UN-Kaufrecht noch als gänzlich unsicher angesehen worden. ${ }^{32}$ Heute gilt es mit mittlerweile 85 Vertragsstaaten ${ }^{33}$ als eines der erfolgreichsten Übereinkommen aller Zeiten auf dem Gebiet des Einheitsprivatrechts. Noch übertroffen wird es in dieser Hinsicht etwa durch das New Yorker Übereinkommen von 1958 über die Anerkennung und Vollstreckung ausländischer Schiedssprüche, ${ }^{34}$ das mit 156 Vertragsstaaten eine noch größere globale Akzeptanz gefunden hat, die allerdings auch durch seine längere Geschichte sowie eine im Vergleich zum Einheitskaufrecht geringere Regelungsdichte zu erklären sein dürfte.

${ }^{30}$ Convention on the Limitation Period in the International Sale of Goods, New York 14.6.1974, 1511 UNTS 3; später geändert Wien 11.4.1980, 1511 UNTS 77.

31 Oben Fn. 2.

32 Bergsten, Thirty-five years (Fn. 28) 7; Schlechtriem, Einheitliches UN-Kaufrecht (Fn. 20) $110 \mathrm{f}$.

${ }^{33}$ Stand: 1.12.2016.

${ }^{34}$ Convention on the Recognition and Enforcement of Foreign Arbitral Awards, New York 10.6.1958, 330 UNTS 3.

Schwerpunkt: Stand und Perspektiven des Einheitsrechts

\section{Digitaler Sonderdruck des Autors mit Genehmigung des Verlages}




\section{Ratifikationsentwicklung und -stand}

Im Nachgang zur Wiener Konferenz verlief die Ratifikation des neuen UN-Kaufrechts zunächst schleppend; die meisten Staaten verhielten sich abwartend. Ein Schritt mit beabsichtigter Signalwirkung war sodann 1986 seine parallele Ratifikation durch die Volksrepublik China, Italien und die USA, die ihre Ratifikationsurkunden in einer gemeinsamen Zeremonie beim Depositar des Übereinkommens hinterlegten und damit demonstrierten, dass das neue Einheitskaufrecht für Staaten unterschiedlicher Wirtschaftssysteme aus unterschiedlichen Regionen gleichermaßen geeignet ist. Nach dem dadurch bewirkten Inkrafttreten des Übereinkommens am 1. Januar 1988 setzten sich die Ratifikationen und Beitritte stetig fort, sodass zu den heutigen 85 Vertragsstaaten 14 der 15 größten Handelsnationen der Welt zählen $^{35}$ und es - vorbehaltlich seiner Abbedingung durch die Parteien ${ }^{36}$ auf nicht weniger als $80 \%$ des Welthandels Anwendung findet. Hierbei fällt auf, dass das UN-Kaufrecht durch Staaten aus allen Teilen der Welt angenommen wurde und auch über die Grenzen einzelner Wirtschaftsräume hinaus ${ }^{37}$ einheitlich gilt; im Gleichklang mit der globalen Vernetzung des Warenhandels hat es den Status eines wahrhaft globalen Einheitsrechts erlangt.

Für die Zukunft darf prognostiziert werden, dass weitere Staaten dem UN-Kaufrecht beitreten werden und diese Entwicklung wohl noch Jahrzehnte andauern wird. Während Ratifikationen und Beitritte in der Vergangenheit jedoch auf Eigeninitiative der Regierungen oder aber - wie etwa jüngst im Fall Brasiliens - auf Anstöße davon profitierender Interessengruppen (Wirtschaft, Rechtsberatung) zurückgingen, spricht manches dafür, dass bei den Nichtvertragsstaaten mit bislang passiver Haltung ein Anschub von außen hilfreich sein könnte. Zwar dürfte die Passivität etwa von Ländern des afrikanischen Kontinents, aber auch Asiens oder einzelner EU-Staaten regelmäßig nicht als Ablehnung des Einheitskaufrechts zu verstehen, sondern auf abweichende parlamentarische und exekutive Prioritäten zurückzuführen sein. In Zukunft dürfte gleichwohl das ,,care and feeding“ ${ }^{\prime 38}$ des Einheitskaufrechts - nämlich dessen aktive ,Vermarktung“ durch das UNCITRALSekretariat $^{39}$ sowie die technische Unterstützung beitrittswilliger Staaten

35 Unter den nach WTO-Zahlen (2015) größten Ex- und Importnationen ist das Vereinigte Königreich dem UN-Kaufrecht bislang nicht beigetreten. Der Vertragsstaatenstatus von Hongkong ist zudem nicht unbestritten; vgl. dazu noch unter V.2. a) (2) (c).

36 Siehe dazu noch unter IV.

37 Siehe zum Zusammenspiel mit von regionalen Organisationen geschaffenem Einheitsrecht noch unten VIII.2.

38 So der treffende Ausdruck von John O. Honnold, Uniform Laws for International Trade: Early ,Care and Feeding' for Uniform Growth, ITBLR 1 (1995) 1.

${ }^{39}$ Dazu schon UNCITRAL Yearbook XIX (1988) 130 ff. sowie Roy Goode, Reflections 
während der Vorbereitung und Durchführung des Übereinkommensbeitritts ${ }^{40}$ - eine noch größere Rolle spielen als schon bisher.

Dessen ungeachtet können innerstaatliche Faktoren dem Einheitsrecht im Wege stehen, und zwar gelegentlich auch dort, wo an dessen Regelungsinhalten gar nichts bemängelt wird. So mag man es als glückliche Fügung ansehen, dass das UN-Kaufrecht in den USA 1986 auf eine innenpolitisch günstige Stimmung traf, weil die US-Einzelstaaten jeder Rechtsetzung des Bundes auf zentralen Gebieten des Vertragsrechts in jüngerer Zeit wieder deutlich kritischer gegenüberstehen. ${ }^{41}$ Dass das UN-Kaufrecht, stünde es heute in den USA zur Ratifikation an, den zuständigen Senat wieder mit 98 zu 0 Stimmen passieren würde (und dies ,trotz erheblicher Widerstände einflussreicher Lobbyisten“"42), darf daher als wenig wahrscheinlich gelten. Andersartige innerstaatliche Gründe haben bislang einen Beitritt des Vereinigten Königreichs verhindert, vor allem in Gestalt des Widerstandes englischer Juristen, welche die gewachsene Rolle des englischen Rechts als am Markt anerkannte Alternative zum UN-Kaufrecht zu verteidigen suchen. ${ }^{43}$ Manches spricht daher dafür, dass das Vereinigte Königreich insoweit auch mittelfristig in ,splendid isolation" verharren wird.

\section{Tendenz zur Rücknahme von Vorbehaltserklärungen}

Die Akzeptanz des Einheitskaufrechts unter seinen Vertragsstaaten hat sich dagegen in jüngerer Zeit noch auf andere Weise manifestiert, die im Einheitsprivatrecht so ein Novum ist: Seit 2011 haben nicht weniger als acht Staaten, die dem UN-Kaufrecht zunächst unter Erklärung eines oder mehrerer der in Art. 92-96 CISG erlaubten Vorbehalte beigetreten waren, diese zurückgenommen (Art. 97(4) CISG), ${ }^{44}$ sodass das Übereinkommen für sie nunmehr ohne die zuvor bestehenden Einschränkungen gilt. Namentlich im Falle des weitreichendsten Vorbehalts - des Ausschlusses von Teil II des

on the Harmonization of Commercial Law, in: Commercial and Consumer Law: National and International Dimensions, hrsg. von Ross Cranston/Roy Goode (1993) 3, 24.

${ }^{40}$ Siehe dazu Luca G. Castellani, Promoting the Adoption of the United Nations Convention on Contracts for the International Sale of Goods (CISG), Vindobona J. of Int'l Commercial Law \& Arbitration 13 (2009) $241 \mathrm{ff}$.

${ }^{41}$ Bergsten, Thirty-five years (Fn. 28) 9.

${ }^{42}$ So zur Ratifikation des UN-Kaufrechts im September 1986 Peter Schlechtriem, Bemerkungen zur Geschichte des Einheitskaufrechts, in: Einheitliches Kaufrecht und nationales Obligationenrecht, hrsg. von dems. (1987) 27, 32.

${ }^{43}$ Vgl. etwa John Stewart Hobhouse, International Conventions and Commercial Law: the Pursuit of Uniformity, L.Q.R. 106 (1990) 530; dagegen Johan Steyn, A Kind of Esperanto?, in: The Frontiers of Liability, hrsg. von Peter Birks, Bd. II (1994) 11.

${ }^{44}$ Siehe hierzu ausführlich Ulrich G. Schroeter, The Withdrawal of Reservations under Uniform Private Law Conventions, Unif. L. Rev. 2015, 1 ff.

Schwerpunkt: Stand und Perspektiven des Einheitsrechts

\section{Digitaler Sonderdruck des Autors mit Genehmigung des Verlages}


UN-Kaufrechts nach Art. 92 CISG durch die nordischen Staaten - ging dessen Rücknahme auf die Praxis zurück, die über die Internationale Handelskammer (ICC) entsprechenden Druck auf die skandinavischen Regierungen ausgeübt hatte. Daran wurde deutlich, dass die anfängliche Skepsis gegenüber den Vertragsschlussbestimmungen des Einheitskaufrechts einer Präferenz zugunsten größerer Einheitlichkeit gewichen war.

Die beschriebene Entwicklung macht deutlich, dass der traditionell kritische Blick unter Rechtsvereinheitlichern auf völkerrechtliche Vorbehalte, der allein deren einheitsreduzierende Wirkung aufnimmt, ${ }^{45}$ einer kritischen Überprüfung bedarf: ${ }^{46}$ Bezieht man auch die Möglichkeit einer Vorbehaltsrücknahme mit ein, so wird sichtbar, dass Vorbehalte es Staaten bei Skepsis gegenüber bestimmten Regelungsinhalten gestatten, das Einheitsrecht gleichsam ,,probezufahren“" ${ }^{47}$ um den Vorbehalt später gegebenenfalls zurückzunehmen. Solche begrenzten Abweichungen vom „Ganz oder gar nicht"-Prinzip des Einheitsrechts erlauben es im Gegenzug, Regelungsbereich und -tiefe einheitsprivatrechtlicher Übereinkommen ambitionierter auszugestalten, als dies ohne Vorbehalte realistisch wäre. Im Ergebnis dienen sie insofern einer umfassenderen Rechtseinheitlichkeit. ${ }^{48}$

\section{UN-Kaufrecht im Rechtsunterricht}

Ein besonders wichtiger Schritt, durch den zugleich die staatliche Akzeptanz des Einheitskaufrechts demonstriert, dessen praktische Anwendung durch staatliche Gerichte ${ }^{49}$ erleichtert und seine Akzeptanz unter Händlern und Rechtsberatern ${ }^{50}$ erhöht würde, wäre eine bessere Verankerung des UN-Kaufrechts im künftigen universitären Rechtsunterricht. Obwohl anerkannt ist, dass die Schulung von Juristen im Einheitsrecht ein rechtspolitisches Desiderat darstellt, wenn man die Vertrautheit der Rechtspraxis mit

${ }^{45}$ James E. Bailey, Facing the Truth: Seeing the Convention on Contracts for the International Sale of Goods as an Obstacle to a Uniform Law of International Sales, Cornell Int'l L.J. 32 (1999) 273, 312; Franco Ferrari, in: Schlechtriem/Schwenzer, Kommentar zum Einheitlichen UN-Kaufrecht $\left(\right.$ CISG) ${ }^{6}$ (2013) Vor Art. 89-101 Rn. 9; Harry M. Flechtner, The Several Texts of the CISG in a Decentralized System: Observations on Translations, Reservations and other Challenges to the Uniformity Principle in Article 7(1), J.L. \& Com. 17 (1998) 187, $193 \mathrm{ff}$.

${ }^{46}$ Hierzu Ulrich G. Schroeter, Reservations and the CISG: The Borderland of Uniform International Sales Law and Treaty Law after Thirty-Five Years, Brook. J. Int'l L. 41 (2015) 203, $226 \mathrm{ff}$.

${ }^{47}$ Dass Vorbehalten diese Rolle auch drei Jahrzehnte nach Schaffung des UN-Kaufrechts weiterhin zukommt, wurde jüngst am Beispiel Vietnams deutlich, das Ende 2015 unter Nutzung des generell im Rückzug begriffenen Vorbehalts nach Art. 96 CISG beitrat.

48 Schroeter, Brook. J. Int'l L. 41 (2015) 203, 234.

49 Dazu noch unter V.

${ }^{50}$ Dazu sogleich unter IV.

Schwerpunkt: Stand und Perspektiven des Einheitsrechts

\section{Digitaler Sonderdruck des Autors mit Genehmigung des Verlages}


seinen Vorschriften bewirken will, ${ }^{51}$ ist das UN-Kaufrecht bislang nämlich nur in wenigen Ländern Bestandteil universitärer Curricula. ${ }^{52}$ Dies zu ändern, sind freilich nicht primär die Staaten aufgerufen, sondern die staatlichen wie privaten Rechtsfakultäten und auch die Rechtspraxis ${ }^{53}$ selbst, in deren Eigeninteresse hinreichende Kenntnisse im Einheitskaufrecht liegen. Eine Rechtspflicht von Vertragsstaaten, das UN-Kaufrecht zum Gegenstand des Rechtsunterrichts zu machen, lässt sich bei dem gegenwärtigen Stand der Rechtsentwicklung dagegen weder aus dem Übereinkommen noch dem allgemeinen Völkervertragsrecht ableiten.

\section{Akzeptanz (oder Ausschluss) durch private Parteien}

Ein Fragenkreis, bei dessen rechtlicher wie empirischer Beurteilung vielfach Unsicherheiten bestehen, ist sodann die Akzeptanz des Einheitskaufrechts unter privaten Parteien.

\section{1. „Opt out“-Modell des Einheitskaufrechts}

Hierbei ist als Ausgangspunkt zunächst entscheidend, dass das UN-Kaufrecht als „opt out“-Einheitsrecht ausgestaltet wurde, das seine Anwendungsvoraussetzungen in Art. 1-5 CISG eigenständig und gänzlich unabhängig vom Anwendungswillen einzelner Parteien definiert. Die genannten Vorschriften verkörpern damit die Überzeugung der Vertragsstaaten, dass das rechtliche Regime des Einheitskaufrechts im Zweifel besser zur Ordnung grenzüberschreitender Kaufvertragsbeziehungen geeignet ist als die nationalen Kaufrechte. Dieser Regelungsansatz überzeugt, weil es um eine generelle, für den Regelfall passende Gestaltungsentscheidung geht, die daher von den ratifizierenden Staaten getroffen werden muss. Das gegenteilige „opt in"-Modell, welches schon die Anwendbarkeit des Einheitsrechts von einer Auswahlentscheidung der Parteien im Einzelfall abhängig macht, wurde bei Schaffung des UN-Kaufrechts aufgrund der Erfahrungen mit

${ }^{51}$ René David, The International Unification of Private Law, in: International Encyclopedia of Comparative Law, Bd.II, Kap. 5 (1971) Anm. 294; Goode, Reflections (Fn. 39) 26f.; Willibald Posch, Fünfundzwanzig Jahre einheitliches internationales Warenkaufrecht in Österreich, ZfRV 2014, 76, 84.

${ }^{52} \mathrm{Zu}$ den USA William S. Dodge, Teaching the CISG in Contracts, J. Legal Educ. 50 (March 2000) 72; zu Österreich Posch, ZfRV 2014, 76, 84.

${ }^{53} \mathrm{Zu}$ den bar associations und deren Zulassungsvoraussetzungen Ingeborg Schwenzer, The Application of the CISG in Light of National Law, IHR 2010, 45, 55. 
dem dahingehenden britischen Vorbehalt zum Haager Kaufrecht ${ }^{54}$ bewusst verworfen. ${ }^{55}$

Art. 6 CISG gestattet es den Parteien jedoch ausdrücklich, bestimmte Vorschriften des Einheitskaufrechts vertraglich abzubedingen oder die Anwendung des Übereinkommens auf ihren Kaufvertrag vollständig auszuschließen. Das Zusammenspiel der Art. 1-5 CISG mit Art. 6 CISG bewirkt, dass es - und dies wird gelegentlich übersehen - auf eine passive Akzeptanz durch die Parteien (oder deren Fehlen) für das Eingreifen des UN-Kaufrechts schlicht nicht ankommt, ${ }^{56}$ und auch eine diesbezügliche Nichtkenntnis auf Seiten der Parteien oder ihrer Rechtsberater keine Rolle spielt. Bedeutsam ist eine mangelnde Akzeptanz des Einheitskaufrechts vielmehr allein dann, wenn sie sich aktiv in einer Ausschlussvereinbarung i.S.d. Art. 6 CISG niederschlägt.

\section{Einigung beider Vertragsparteien als Ausschlussvoraussetzung}

Eine solche Ausschlussvereinbarung setzt ihrerseits eine diesbezügliche Übereinstimmung beider Vertragsparteien voraus, die sich zudem hinreichend deutlich geäußert haben muss. Die internationale Gerichtspraxis zu Art. 6 CISG stellt dabei strenge Anforderungen an die Deutlichkeit des Abwahlwillens, ${ }^{57}$ und namentlich die häufig in Standardklauseln enthaltene Wahl des Rechts eines CISG-Vertragsstaats (z.B. „Für diesen Vertrag gilt deutsches Recht") wird ganz einheitlich nicht als Ausschlussvereinbarung angesehen, weil das UN-Kaufrecht Bestandteil jedes Vertragsstaatenrechts ist. ${ }^{58}$ Vor allem ist aber erforderlich, dass ein etwaiges Ausschlussangebot in Gestalt einer AGB-Klausel - und entsprechende Klauseln sind für die vielfach kolportierten Eindrücke aus der nicht spezialisierten deutschen Rechtspraxis wohl prägend - durch die Gegenpartei auch angenommen wird, weil der Ausschluss andernfalls eben gar nicht zustande kommt. An einer solchen Annahme fehlt es aber regelmäßig, weil die Gegenpartei vielfach eine abweichende Rechtswahlklausel (in der Regel zugunsten des eigenen Heimat-

54 Dazu bereits oben unter II.2.

55 Deutlich zur Ablehnung eines Antrags auf der Wiener Konferenz von 1980, zumindest wieder einen entsprechenden Vorbehalt zuzulassen, Rolf Herber, Anwendungsbereich des UNCITRAL-Kaufrechtsübereinkommens, in: Das UNCITRAL-Kaufrecht im Vergleich zum österreichischen Recht, hrsg. von Peter Doralt (1985) 28, 32: „, Sie hätte dies auch um den Preis des Scheiterns der Konferenz nicht tun dürfen [... “.

56 Burghard Piltz, Internationales Kaufrecht ${ }^{2}$ (2008) Rn. 2-111.

57 BP Oil International v. Empresa Estatal Petroleos de Ecuador, 332 F.3d 333 (5th Cir. 2003); Schlechtriem/Schroeter, Int. UN-Kaufrecht (Fn. 29) Rn. 49 ff.

58 Statt vieler BGer. 17.7.2007 - 4C.94/2006, IHR 2007, 206, 207f.; OGH 22.10.2001$1 \mathrm{Ob} 77 / 01 \mathrm{~g}$, IHR 2002, 24, 26; BGH 11.5.2010 - VIII ZR 212/07, NJW-RR 2010, 1217 Tz. 15; Schlechtriem/Schwenzer/Ferrari (Fn. 45) Art. 6 Rn. 22 m.w.Nachw.

Schwerpunkt: Stand und Perspektiven des Einheitsrechts

\section{Digitaler Sonderdruck des Autors mit Genehmigung des Verlages}


rechts) verwendet, sodass sich beide Klauseln mangels Übereinstimmung neutralisieren - und zwar selbst dann, wenn beide einen Ausschluss des UN-Kaufrechts vorsehen sollten. ${ }^{59}$

\section{Empirie und Folgerungen}

Im Ergebnis überrascht es daher nicht, dass es keine belastbaren empirischen Beweise für einen häufigen Ausschluss des Einheitskaufrechts gibt. ${ }^{60}$ Dies liegt zunächst daran, dass aus der Praxis nicht weniger Staaten (wie etwa der Niederlande ${ }^{61}$ oder Österreichs ${ }^{62}$ ) ein hohes Maß an Akzeptanz des CISG berichtet wird, während anekdotische Eindrücke des Inhalts, das UN-Kaufrecht werde ,regelmäßig“ abbedungen, namentlich aus Deutschland stammen. ${ }^{63}$ Entscheidend ist angesichts des Erfordernisses einer Parteieinigung $^{64}$ jedoch vor allem, dass einseitige Standardklauseln über einen tatsächlichen Ausschluss nichts aussagen, da sie bestenfalls die Ausgangsposition einer der Vertragsparteien zu Beginn des Verhandlungs- und Einigungsprozesses abbilden - und selbst in dieser Funktion häufig nicht (oder nicht rechtzeitig) in die Verhandlungen eingeführt werden. Aus diesem Grund ist es auch sinnlos, aus den in einer bestimmten Jurisdiktion verwandten Standardklauseln Schlüsse auf die praktische Bedeutung des UNKaufrechts abzuleiten: ${ }^{65}$ Blickte man zur Ermittlung des auf schwedisch-polnische Kaufverträge anwendbaren Rechts z.B. auf die von schwedischen Unternehmen verwandten AGB-Klauseln, so wäre das sich daraus ergebende Bild mit hoher Wahrscheinlichkeit eines einer nahezu 100\%-igen An-

59 Schlechtriem/Schroeter, Int. UN-Kaufrecht (Fn. 29) Rn. 54.

${ }^{60}$ Filip De $L y$, The relevance of the Vienna Convention for International Sales Contracts: Should we stop contracting it out?, Bus. L. Int'l 4 (2003) 241, 242 ff.; Ulrich G. Schroeter, Empirical Evidence of Courts' and Counsels' Approach to the CISG (with Some Remarks on Professional Liability), in: International Sales Law - A Global Challenge, hrsg. von Larry A. DiMatteo (2014) 649, $650 \mathrm{ff}$.

${ }^{61}$ De Ly, Bus. L. Int'l 4 (2003) 241, 244.

62 Posch, ZfRV 2014, 76, 79.

63 Vgl. etwa Reinhard Fischer, Vor- und Nachteile des Ausschlusses des UN-Kaufrechts aus Sicht des deutschen Exporteurs (2008) $2 \mathrm{f}$.

${ }^{64}$ Oben IV.2.

${ }^{65}$ So statt mancher aber jüngst John F. Coyle, The Role of the CISG in U.S. Contract Practice: An Empirical Study, U. Pa. J. Int'1 L. (erscheint 2016/17), dessen verwandter, aus der EDGAR-Datenbank der U.S. Securities and Exchange Commission (SEC) generierter Datensatz auch deshalb als untauglich erscheint, weil er von vornherein nur ,wesentliche“ (,material“) Verträge umfasst, die zudem gerade außerhalb des üblichen Geschäftsverkehrs geschlossen wurden (,,not made in the ordinary course of business“, 17 C.F.R. $\$ 229.601(b)(10)$ ): Die typische Vertragspraxis ist davon mangels Publizitätspflichtigkeit also überhaupt nicht abgedeckt, was durch Coyles Befund bestätigt wird, dem zufolge auf nicht weniger als $69 \%$ der gefundenen Verträge mit CISG-Ausschlussklausel das CISG gar nicht anwendbar war - vor allem, weil es sich nicht einmal um Warenkaufverträge handelte(!).

Schwerpunkt: Stand und Perspektiven des Einheitsrechts

\section{Digitaler Sonderdruck des Autors mit Genehmigung des Verlages}


wendbarkeit schwedischen Rechts (unter mehr oder weniger häufigem Ausschluss des UN-Kaufrechts), während ein Abstellen auf die AGB-Gestaltungspraxis polnischer Unternehmen eine nahezu 100\%ige Anwendbarkeit polnischen Rechts ergäbe (wiederum mit gelegentlichem Ausschluss des UN-Kaufrechts). Es ist evident, dass beides nicht richtig sein kann und entsprechend angelegte „empirische“ Erhebungen daher keinen Erkenntnisgewinn versprechen.

\section{Auslegung durch Gerichte und Schiedsgerichte}

Angesichts des vergleichsweise weit fortgeschrittenen Ratifikationsstandes des UN-Kaufrechts ${ }^{66}$ steht heute vor allem die Anwendung und Interpretation des Übereinkommens durch Gerichte und Schiedsgerichte im Mittelpunkt der Aufmerksamkeit.

\section{Zahlen}

Dass das Einheitskaufrecht in der grenzüberschreitenden Praxis tatsächlich zur Anwendung gelangt, lässt sich an den mittlerweile 3.152 Gerichtsurteilen und Schiedssprüchen zum Übereinkommen ablesen, die in den einschlägigen Datenbanken ausgewiesen sind. ${ }^{67}$ Die größte Entscheidungszahl stammt dabei mit 534 Urteilen aus Deutschland, es folgen China (432), Russland (305), die Niederlande (268), die Schweiz (212), die USA (183), Frankreich (164), Österreich (145), Belgien (144) und Spanien (114). Aus weiteren 41 Vertrags- und Nichtvertragsstaaten werden zwei- oder einstellige Entscheidungszahlen berichtet.

Diese Zahlen taugen freilich aus einer Reihe von Gründen nur sehr bedingt als Indikator der praktischen Bedeutung des UN-Kaufrechts. ${ }^{68}$ So erfassen sie notwendigerweise nur die öffentlich bekannten Gerichtsentscheidungen und bilden daher nur einen (vermutlich kleinen) Teilausschnitt aller tatsächlich ergangenen Urteile zum CISG (die sprichwörtliche „Spitze des Eisbergs") ab; die Gesamtzahl gerichtlicher Verfahren zum Einheitskaufrecht dürfte signifikant höher liegen. Welche und wie viele Gerichtsentscheidungen in einzelnen Staaten veröffentlicht werden, hängt dabei in der Regel maßgeblich von lokalen Usancen ab, die mit dem angewandten ma-

66 Oben III.1.

${ }^{67}$ So die Anzahl der in der Albert H. Kritzer Database der Pace Law School, New York, $<$ www.cisg.law.pace.edu>, gelisteten Entscheidungen; die Datenbank CISG online der Universität Basel, <www.cisg-online.ch>, weist 2.654 Entscheidungen aus.

${ }^{68} \mathrm{Vgl}$. hierzu Thomas Neumann, Is the Albert H. Kritzer Database Telling Us More Than We Know?, Pace Int'l L. Rev. 27 (2015) $119 \mathrm{ff}$.

Schwerpunkt: Stand und Perspektiven des Einheitsrechts

\section{Digitaler Sonderdruck des Autors mit Genehmigung des Verlages}


teriellen Recht wenig oder nichts zu tun haben. So ist etwa die Anzahl der bekannten österreichischen Urteile zum CISG im Verhältnis zur Größe des Landes überraschend hoch; aus Österreich stammen relativ betrachtet sogar mehr höchstrichterliche Entscheidungen als aus jeder anderen CISG-Jurisdiktion. ${ }^{69}$ Beides dürfte freilich auch damit zusammenhängen, dass in Österreich generell vergleichsweise viele Verfahren bis vor den Obersten Gerichtshof (OGH) gelangen und dessen Urteile zudem weit umfassender publiziert werden als Instanzurteile. In Deutschland, wo statistisch lediglich $1,2 \%$ der erstinstanzlichen Zivilverfahren bis zum BGH getrieben werden, ${ }^{70}$ aber jährlich im Durchschnitt etwa zwei BGH-Urteile zum UN-Kaufrecht ergehen, müssten daher jedes Jahr ca. 160 landgerichtliche Prozesse zum Einheitskaufrecht beendet werden - demgegenüber nimmt sich die bekannte Zahl von insgesamt 534 deutschen CISG-Urteilen gering aus.

Die Anzahl der in einzelnen Ländern ergangenen Gerichtsurteile wird im Übrigen nicht nur durch die Bedeutung des Einheitskaufrechts „in“ dem jeweiligen Land, sondern (angesichts der wegen Art. 1(1) CISG zwingend Parteien aus unterschiedlichen Ländern betreffenden Vertragsbeziehung) noch mehr durch die Bedeutung des Landes als Forum für internationale Streitbeilegungen beeinflusst, ${ }^{71}$ die in der Regel vor allem von der Funktionsfähigkeit des dortigen Gerichtssystems abhängt. Aus diesem Grund liegt etwa Rechtsprechung zum UN-Kaufrecht aus dem Nichtvertragsstaat England vor, ${ }^{72}$ aber kaum aus Vertragsstaaten ohne bewährte und im grenzüberschreitenden Verkehr akzeptierte Gerichtsbarkeit. Und schließlich wäre selbst dann, wenn die tatsächliche Gesamtzahl der Gerichtsverfahren zum Einheitskaufrecht bekannt wäre, dessen relative praktische Bedeutung allein daran nicht ablesbar, weil hierzu auch die Zahl der sonstigem (nationalem) Kaufrecht unterliegenden grenzüberschreitenden Streitfälle bekannt sein müsste, die jedoch gleichermaßen im Dunkeln liegt.

\section{Vorgaben des Art. 7(1) CISG und ihre praktische Umsetzung}

Aus einheitsrechtlicher Sicht von zentraler Bedeutung ist vor allem die internationale Einheitlichkeit der Übereinkommensauslegung, weil erst durch sie das Ziel der Rechtsvereinheitlichung - die Herstellung von Rechtsgleichheit und daraus folgender Rechtssicherheit im internationalen

69 Posch, ZfRV 2014, 76, 79.

${ }^{70}$ Im Jahre 2013 standen 348.651 vor den Landgerichten erledigte Zivilverfahren 4.228 vor dem BGH erledigten Zivilsachen gegenüber; vgl. Statistisches Bundesamt, Rechtspflege: Zivilgerichte 2013 (2014) 37, 96.

71 Dies übersieht Neumann, Pace Int'l L. Rev. 27 (2015) 119, $145 \mathrm{f}$.

72 Siehe etwa Kingspan Environmental Ltd \& Ors v Borealis A/S \& Anor [2012] EWHC 1147 (Comm).

Schwerpunkt: Stand und Perspektiven des Einheitsrechts

\section{Digitaler Sonderdruck des Autors mit Genehmigung des Verlages}


Rechtsverkehr ${ }^{73}$ - verwirklicht wird. Die Schaffung und Inkraftsetzung eines einheitsrechtlichen Textes stellt insofern nur den ersten Schritt hin zur Rechtsgleichheit dar, der einer Ergänzung und gleichsam „Verlängerung“ durch die uniforme Interpretation der in Kraft gesetzten Rechtsvorschriften bedarf, soll die Einheitlichkeit nicht nur auf dem Papier bestehen. Eine solche inhaltlich einheitliche Auslegung des UN-Kaufrechts ist bislang - wie an dieser Stelle bereits vorweggenommen werden kann - im Wesentlichen geglückt; ${ }^{74}$ deutlich skeptischere Prognosen in dieser Hinsicht ${ }^{75}$ konnten damit in der Praxis widerlegt werden.

a) Steuerung der Interpretation durch Auslegungsziele

Hauptsächliches Mittel zur Bewirkung der Einheitlichkeit ist Art. 7(1) CISG, der die Gerichte der Vertragsstaaten zur Beachtung von drei Auslegungszielen verpflichtet. Die Vorschrift gilt als wichtigste Norm des Einheitskaufrechts $^{76}$ und hat zudem vielen anderen Übereinkommen als Vorbild gedient, die wortgleiche ${ }^{77}$ oder geringfügig ergänzte ${ }^{78}$ Bestimmungen aufweisen.

73 Kropholler, Int. Einheitsrecht (Fn. 8) 9 f.

74 So auch Michael Bridge, The CISG from the Common Lawyer's Point of View, in: FS Ulrich Magnus (2014) 161, 175: ,very large measure of international uniformity“; Posch, ZfRV 2014, 76, 78: ,hohes Maß an internationaler Entscheidungskonvergenz"; wohl a.A. Schwenzer, IHR 2010, 45, $46 \mathrm{ff}$.

${ }^{75}$ Haimo Schack, Internationales Zivilverfahrensrecht ${ }^{1}$ (1991) Rn. 85: „Einheitsrecht hat die Tendenz, sich in der Praxis auseinanderzuentwickeln. [...] Dieses Schicksal wird z. B. das Wiener UN-Kaufrecht vom 11.4.1980 erleiden, das mit seiner häufigen Verwendung unbestimmter Rechtsbegriffe (,angemessen") zu divergierender Auslegung geradezu einlädt"; Kötz, RabelsZ 50 (1986) 1, 7; aus jüngerer Zeit Christopher Sheaffer, The Failure of the United Nations Convention on Contracts for the International Sale of Goods and a Proposal for a New Uniform Code in International Sales Law, Cardozo J. Int'l \& Comp. L. 15 (2007) 461.

76 Pilar Perales Viscasillas, in: Kröll/Mistelis/Perales Viscasillas, UN Convention on Contracts for the International Sale of Goods (CISG) (2011) Art. 7 Rn. 2; in diese Richtung auch Bridge, International Sale (Fn. 22) Rn. 10.39. Skeptischer Neumann, Pace Int'1 L. Rev. 27 (2015) 119, 125: ,the wishbone of the CISG rather than its backbone.“

77 Art. 6(1) Convention on Agency in the International Sale of Goods, Genf 17.2.1983; Art. 4 UN Convention on International Bills of Exchange and International Promissory Notes, New York 9.12.1988; Art. 5 UN Convention on Independent Guarantees and Standby Letters of Credit, New York 11.12.1995; Art.5(1) UN Convention on the Use of Electronic Communications in International Contracts, New York 23.11.2005; Art. 2 UN Convention on Contracts for the International Carriage of Goods Wholly or Partly by Sea (,,Rotterdam Rules“), New York 11.12.2008.

78 Die Art. 7(1) CISG nachgebildeten Vorschriften einiger Übereinkommen nehmen zusätzlich auf den in der jeweiligen Präambel genannten Gegenstand und Zweck Bezug; so Art.4(1) UNIDROIT Convention on International Factoring und Art. 6(1) UNIDROIT Convention on International Financial Leasing, beide Ottawa 28.5.1988; Art. 7(1) UN Convention on the Assignment of Receivables in International Trade, New York 12.12.2001. Art. 5(1) Übereinkommen von Kapstadt (oben Fn. 6) nennt darüber hinaus noch die Förderung der Vorhersehbarkeit.

Schwerpunkt: Stand und Perspektiven des Einheitsrechts

\section{Digitaler Sonderdruck des Autors mit Genehmigung des Verlages}


(1) Die Auslegungsziele im Überblick

Art. 7(1) CISG schreibt im Einzelnen vor, dass bei der Auslegung des UN-Kaufrechts sein internationaler Charakter und die Notwendigkeit zu berücksichtigen sind, seine einheitliche Anwendung und die Wahrung des guten Glaubens im internationalen Handel zu fördern. Dagegen macht die Vorschrift keine Vorgaben zur Interpretationsmethode, die damit den nationalen Rechten überlassen bleibt; ${ }^{79}$ Art. 7(1) CISG gibt mit anderen Worten Interpretationsziele vor, nicht aber den Weg dorthin. ${ }^{80}$ Auch eine Auslegung des Einheitskaufrechts auf Grundlage seiner ökonomischen Analyse ${ }^{81}$ ist daher nicht per se ausgeschlossen. Freilich sind Rückwirkungen auf die verwandten Interpretationsmethoden möglich, soweit das Erreichen der Auslegungsziele dies erfordert, sodass etwa die Beachtung der Entstehungsgeschichte des Übereinkommens für unabdingbar gehalten wird, obwohl common law-Jurisdiktionen dieser traditionell zurückhaltend gegenüberstehen. ${ }^{82}$ Zudem verlangt Art. 7(1) CISG lediglich das „Berücksichtigen“ der darin erwähnten Auslegungsziele (,,regard is to be had to“) und macht damit deutlich, dass andere Ziele ebenfalls zum Tragen kommen können, darunter namentlich die gerechte Entscheidung des Einzelfalls.

(a) Internationaler Charakter des Übereinkommens. - Unter den drei Auslegungszielen wird sodann als erstes die Berücksichtigung des internationalen Charakters des Übereinkommens genannt. Dies wird allgemein als Pflicht zur autonomen Auslegung des UN-Kaufrechts verstanden, ${ }^{83}$ d. h. zur Interpretation aus sich selbst und aus dem Gesamtzusammenhang des Übereinkommens heraus, ohne Rückgriff auf zu Normen des unvereinheitlichten nationalen Rechts entwickelte Auslegungsansätze und Rechtsprechung. ${ }^{84}$ Die geforderte Beachtung des internationalen Charakters des Einheitskaufrechts hat damit eine ,vertikale“ Stoßrichtung, indem sie das internationale Einheitsrecht von den nationalen Rechtsordnungen absetzt.

Vor diesem Hintergrund bedarf die kontrovers diskutierte Frage, ob das UN-Kaufrecht einer rechtsvergleichenden Auslegung zugänglich ist, zu-

79 Str., a. A. Schlechtriem/Schwenzer/Ferrari (Fn. 45) Art. 7 Rn. 29; wiederum anders Ingeborg Schwenzer/Pascal Hachem, in: Schlechtriem/Schwenzer, Commentary on the UN Convention on the International Sale of Goods (CISG) ${ }^{4}$ (2016) Art. 7 Rn. 20.

${ }^{80}$ Schlechtriem/Schroeter, Int. UN-Kaufrecht (Fn. 29) Rn. 103.

${ }^{81}$ Siehe dazu Marta Cenini/Franceso Parisi, An Economic Analysis of the CISG, in: CISG Methodology, hrsg. von André Janssen/Olaf Meyer (2009) $151 \mathrm{ff}$.

${ }^{82}$ Bridge, International Sale (Fn. 22) Rn. 10.40; John O. Honnold/Harry M. Flechtner, Uniform Law for International Sales under the 1980 United Nations Convention ${ }^{4}$ (2009) Rn. $88 \mathrm{ff}$.

${ }^{83}$ BGH 2.3.2005 - VIII ZR 67/04, NJW-RR 2005, 1218, 1219; Michael Joachim Bonell, in: Bianca/Bonell, Commentary on the International Sales Law (1987) Art. 7 Anm. 2.2.2; Rolf Herber/Beate Czerwenka, Internationales Kaufrecht (1991) Art. 7 Rn. 4; Ulrich Magnus, in: Staudinger, Kommentar zum BGB (2013) Art. 7 CISG Rn.12; Schlechtriem/Schwenzer/ Schwenzer/Hachem (Fn. 79 ) Art. 7 Rn. 8.

${ }^{84}$ BGH 2.3.2005, NJW-RR 2005, 1218, 1219.

Schwerpunkt: Stand und Perspektiven des Einheitsrechts

\section{Digitaler Sonderdruck des Autors mit Genehmigung des Verlages}


nächst einer begrifflichen Konkretisierung: Versteht man darunter die Interpretation des Übereinkommens anhand multipler, untereinander verglichener nationaler Rechte ${ }^{85}$ so ist eine solche Auslegung mit dem internationalen Charakter des Übereinkommens unvereinbar, ${ }^{86}$ obwohl diese hier nicht nur an einem einzelnen nationalen Referenzmaßstab (sondern an mehreren, bei realistischer Prognose aber gleichwohl nur wenigen nationalen Rechten) ausgerichtet würde. Meint man mit Rechtsvergleichung dagegen die Berücksichtigung der Rechtsprechung aus unterschiedlichen Staaten zum Übereinkommen selbst, ${ }^{87}$ so ist dieser Interpretationsansatz nicht nur unproblematisch mit Art.7(1) CISG vereinbar, sondern verwirklicht zugleich das weitere, als nächstes anzusprechende Auslegungsziel der einheitlichen Anwendung des Übereinkommens.

(b) Einheitliche Anwendung des Übereinkommens. - In Gestalt der Berücksichtigung der Notwendigkeit, die einheitliche Anwendung des UN-Kaufrechts zu fördern, schreibt Art. 7(1) CISG seinen Adressaten - nämlich der staatlichen Gerichtsbarkeit der Vertragsstaaten ${ }^{88}$ als demjenigen vertragsstaatlichen Organ, in dessen Hand die Interpretation und Anwendung des Übereinkommens liegt - vor allem vor, bei ihrer Tätigkeit bestehende ausländische Rechtsprechung zum UN-Kaufrecht zu beachten. ${ }^{89}$ Es handelt sich nicht lediglich um einen unverbindlichen Appell, sondern um eine echte Rechtspflicht, ${ }^{90}$ deren präziser Inhalt freilich noch nicht vollständig geklärt ist. Weitgehende Einigkeit besteht immerhin darüber, dass Art. 7(1) CISG keine rechtliche Bindung an ausländische Präjudizien im Sinne einer stare decisis anordnet, sondern deren Berücksichtigung als mögliche persuasive authority genügen lässt. ${ }^{91} \mathrm{Ob}$ das Auslegungsziel daneben auch die (sicherlich

85 So statt vieler Schlechtriem/Schwenzer/Schwenzer/Hachem (Fn. 79) Art. 7 Rn. 24.

${ }^{86}$ Herber/Czerwenka, Int. Kaufrecht (Fn. 83) Art.7 Rn.9; Schlechtriem/Schroeter, Int. UN-Kaufrecht (Fn. 29) Rn.110; Schlechtriem/Schwenzer/Ferrari (Fn. 45) Art. 7 Rn. 40; a.A. Schlechtriem/Schwenzer/Schwenzer/Hachem (Fn. 79) Art. 7 Rn. 24; Staudinger/Magnus (Fn. 83) Art. 7 CISG Rn. 37: wünschenswert.

87 So Basedow, RabelsZ 81 (2017) 1, 20 f. (in diesem Heft); Kropholler, Int. Einheitsrecht (Fn. 8) $280 \mathrm{f}$.

${ }^{8}$ Kaum erörtert worden ist bislang, ob Art. 7(1) CISG sich an die Gerichtsbarkeit jedes Vertragsstaates in ihrer Gesamtheit oder aber unmittelbar an jedes einzelne vertragsstaatliche Gericht richtet. Hier sprechen die besseren Gründe für die Annahme, dass das Übereinkommen jedem Vertragsstaat die Organisation seines Gerichtssystems überlassen will, sodass die einzelnen Gerichte nur im Rahmen ihrer Zuständigkeit zu dessen Anwendung verpflichtet sind.

89 Honnold, ITBLR 1 (1995) 1, 8; Schlechtriem/Schwenzer/Schwenzer/Hachem (Fn. 79) Art. 7 Rn. 10; Staudinger/Magnus (Fn. 83) Art. 7 CISG Rn. 21.

90 Dies gilt für alle Auslegungsziele des Art.7(1) CISG gleichermaßen; so auch Joseph Lookofsky, Digesting CISG Case Law: How Much Regard Should We Have?, Vindobona J. of Int'l Commercial Law \& Arbitration 8 (2004) 181, 184; Neumann, Pace Int'l L. Rev. 27 (2015) 119, 127; Schlechtriem/Schwenzer/Schwenzer/Hachem (Fn. 79) Art. 7 Rn. 7.

91 TeeVee Toons, Inc. et al v. Gerhard Schubert GmbH, 2006 WL 2463537 (S.D.N.Y.); BGer. 2.4.2015 -4A_614/2014, IHR 2015, 250, 257; Lookofsky, Vindobona J. of Int'l Commercial

Schwerpunkt: Stand und Perspektiven des Einheitsrechts

\section{Digitaler Sonderdruck des Autors mit Genehmigung des Verlages}


wünschenswerte) Beachtung ausländischen Schrifttums verlangt, ${ }^{92}$ ist einstweilen noch unsicher. Insgesamt besitzt das zweite Auslegungsziel damit eine „horizontale“ Stoßrichtung, weil es die Gerichte jedes Vertragsstaates zwingt, den Blick über dessen Grenzen hinaus auch auf andere Vertragsstaaten und die dort angefallene Anwendungspraxis zu richten. Seine Verwirklichung ist eine potentiell aufwändige Daueraufgabe, auf deren bisherige Bewältigung im Folgenden ${ }^{93}$ noch näher einzugehen sein wird.

(c) Wahrung des guten Glaubens im internationalen Handel. - Das dritte und letzte Auslegungsziel - die Förderung der Wahrung des guten Glaubens im internationalen Handel - war bei Schaffung des UN-Kaufrechts am stärksten umstritten. Grund hierfür war, dass dieses Auslegungsziel nicht nur gleichsam wertungsfrei auf eine ,vertikale“ Unterscheidung oder einen „horizontalen“ Auslegungsgleichklang zielt, sondern mit der Wahrung des guten Glaubens (good faith) eine inhaltliche Wertung in die Übereinkommensinterpretation einführt, deren genauer Gehalt nicht von vornherein abschätzbar ist. In der sonstigen Einheitsrechtsetzung hat es daher eine zurückhaltendere Akzeptanz erfahren, und verschiedene Übereinkommensnormen, die im Übrigen Art. 7(1) CISG nachgebildet wurden, erwähnen den guten Glauben nicht. ${ }^{94}$ Unter dem UN-Kaufrecht wird das Auslegungsziel bis heute nicht ganz einheitlich verstanden, wobei man insbesondere streitet, ob der gute Glauben im internationalen Handel getreu dem klaren Wortlaut des Art. 7(1) CISG nur bei der Interpretation des Übereinkommens ${ }^{95}$ oder auch der Beurteilung von Parteipflichten und -verhalten ${ }^{96} \mathrm{zu}$ berücksichtigen ist.

Law \& Arbitration 8 (2004) 181, 184; Wolfgang Witz, in: Witz/Salger/Lorenz, International Einheitliches Kaufrecht ${ }^{2}$ (2016) Art. 7 Rn. 11.

${ }_{92}$ Dafür etwa Honnold, ITBLR 1 (1995) 1, 9; Staudinger/Magnus (Fn. 83) Art. 7 CISG Rn. 21; Witz/Salger/Lorenz/Witz (vorige Fn.) Art. 7 Rn. 10.

${ }_{93}$ Unter V.2. a) (2).

${ }^{94}$ Art. 16 Hague Convention on the Law Applicable to Contracts for the International Sale of Goods, Den Haag 22.12.1986; Art. 14 UN Convention on the Liability of Operators of Transport Terminals in International Trade, Wien 19.4.1991; Art. 23 Hague Convention on Choice of Court Agreements, Den Haag 30.3.2005; Art. 13 Hague Convention on the Law Applicable to Certain Rights in Respect of Securities held with an Intermediary, Den Haag 5.7.2006. Vgl. auch Art. 1.6(1) UNIDROIT Principles of International Commercial Contracts 2010, die allerdings in Art. 1.7(1) die Parteien ausdrücklich zur Beachtung von Treu und Glauben verpflichten.

${ }_{95}$ Bridge, International Sale (Fn. 22) Rn. 10.41; Schlechtriem/Schroeter, Int. UN-Kaufrecht (Fn. 29) Rn. 100f.

${ }_{96}$ Bianca/Bonell/Bonell (Fn. 83) Art.7 Anm.2.4.1; Staudinger/Magnus (Fn. 83) Art.7 CISG Rn. 10.

Schwerpunkt: Stand und Perspektiven des Einheitsrechts

\section{Digitaler Sonderdruck des Autors mit Genehmigung des Verlages}


(2) Die Beachtung der Auslegungsziele in der gerichtlichen Praxis

Zieht man nach nahezu drei Jahrzehnten praktischer Anwendung des UN-Kaufrechts einen Zwischenbefund, so lässt sich konstatieren, dass seine einheitliche Interpretation auf diesem Wege im Großen und Ganzen erreicht wurde. ${ }^{97}$

(a) Übereinkommensstruktur als Faktor. - Wesentlich erleichtert wurde dies durch eine Strukturentscheidung der Übereinkommensverfasser, deren Bedeutung nicht selten unterschätzt wird: Die Haager Einheitlichen Kaufgesetze von $1964^{98}$ waren noch als klassische lois uniformes konzipiert gewesen, deren Text von jedem Vertragsstaat in seiner jeweiligen Heimatsprache in nationales Recht umzusetzen war; der deutsche Richter wandte auf einen deutsch-niederländischen Kaufvertrag daher das deutsche Einheitliche Kaufgesetz (EKG) an, während sein niederländischer Kollege das niederländische Eenvormige Koopwet zur Anwendung brachte. Schon die Ausgestaltung der umsetzenden Regelungen als Gesetzesvorschriften der nationalen Rechte lässt deren einheitsrechtlichen Charakter aber in den Hintergrund treten, ${ }^{99}$ und selbst ausdrückliche Hinweisnormen, wie sie das deutsche Recht etwa in Gestalt des Art. 36 EGBGB a. F. kannte, vermögen dem kaum effektiv abzuhelfen. ${ }^{100}$

Dass das UN-Kaufrecht demgegenüber als einheitliches, sowohl vertragsschluss- und kaufrechtliche Vorschriften als auch völkerrechtliche Rahmenbestimmungen zusammenfassendes Übereinkommen (convention intégrale) abgefasst wurde, ${ }^{101}$ hat zur Folge, dass Rechtsanwender nicht länger mit nationalen Umsetzungsnormen, sondern unmittelbar mit dem Übereinkommenstext arbeiten, ${ }^{102}$ der zudem in seinen sechs authentischen Sprachfassungen zur Anwendung gelangt (der deutsche Wortlaut ist nicht mehr als eine rechtlich unverbindliche Übersetzung $\left.{ }^{103}\right)$. Diese auf den ersten Blick lediglich rechtstechnische Formwahl hat erheblich zur international einheitlichen Anwendung des Einheitskaufrechts beigetragen.

(b) Berücksichtigung des internationalen Charakters des UN-Kaufrechts. - Sowohl die Verwirklichung des Ziels der einheitlichen Anwendung als auch

97 Oben Fn. 17.

98 Siehe oben II.2.

99 Jürgen Basedow, Depositivierungstendenzen in der Rechtsprechung zum Internationalen Einheitsrecht, in: FS 50 Jahre BGH, Bd. II (2000) 777, 790; Enderlein/Maskow/Strohbach, Int. Kaufrecht (Fn. 4) 28; Kropholler, Int. Einheitsrecht (Fn. 8) 102.

100 Eckart Brödermann, Paradigmenwechsel im Internationalen Privatrecht: Zum Beginn einer neuen Ära seit 17.12.2009, NJW 2010, 807, 812; Dieter Martiny, in: Münchener Kommentar zum BGB ${ }^{4}$ (2006) Art. 36 EGBGB Rn. 7 f., 10 f.

101 Dazu UNCITRAL Yearbook VI (1975) 50 Nr. 13; G. Beate Czerwenka, Rechtsanwendungsprobleme im internationalen Kaufrecht (1988) 124.

102 Herber/Czerwenka, Int. Kaufrecht (Fn. 83) Einführung Rn. 3.

103 Herber/Czerwenka, Int. Kaufrecht (Fn. 83) Einführung Rn. 4; Werner Melis, in: Honsell, Kommentar zum UN-Kaufrecht ${ }^{2}$ (2010) Art. 7 Rn. 10.

Schwerpunkt: Stand und Perspektiven des Einheitsrechts

\section{Digitaler Sonderdruck des Autors mit Genehmigung des Verlages}


die Berücksichtigung des internationalen Charakters des Einheitskaufrechts - beide Auslegungsziele sind insofern eng verwandt ${ }^{104}$ - lassen sich u. a. an dem Umfang ablesen, in dem in der gerichtlichen Praxis auf ausländische Urteile zum CISG Bezug genommen wird. Solche Bezugnahmen finden sich in 19 der bislang 534 veröffentlichten deutschen Urteile zum Einheitskaufrecht (also 3,5\%); sie kommen auch in der Rechtsprechung zahlreicher anderer Vertragsstaaten vor, ${ }^{105}$ wobei ihre Häufigkeit fast überall im Laufe der Zeit zugenommen hat. Besonders umfangreiche Verweise enthalten dabei einzelne italienische Urteile, in denen jeweils nahezu 40 ausländische Judikate zitiert werden. ${ }^{106}$

Dem internationalen Charakter des UN-Kaufrechts wird methodisch überwiegend durch dessen autonome Auslegung ${ }^{107}$ Rechnung getragen, indem das Übereinkommen aus sich selbst heraus und ohne Rückgriff auf zum nationalen Recht ergangene Rechtsprechung ${ }^{108}$ interpretiert wird. Es finden sich freilich auch Gegenbeispiele, vor allem in Gestalt einer mittlerweile verfestigten Rechtsprechungslinie in den USA, wo UN-Kaufrechtsnormen in unreflektiertem Anschluss an ein frühes Urteil zum CISG $^{109}$ teilweise anhand von Rechtsprechung zum angeblich wortlautähnlichen Uniform Commercial Code (UCC) ausgelegt werden. ${ }^{110}$ Dass auch harsche Kritik US-amerikanischer Autoren ${ }^{111}$ solche klaren Verstöße gegen Art.7(1) CISG $^{112}$ bislang nicht zu verhindern vermochte, deutet an, dass die Orientierung an innerstaatlichen Präjudizien bisweilen mit Art.7(1) CISG in

${ }^{104}$ Honnold/Flechtner, Uniform Law (Fn. 82) Rn. 86.

105 Eine Liste entsprechender Urteile (Stand 2009) findet sich bei Camilla Baasch Andersen, The Global Jurisconsultorium of the CISG Revisited, Vindobona J. of Int'l Commercial Law \& Arbitration 13 (2009) 43, 64ff.

106 Trib. Vigevano 12.7.2000 (Rheinland Versicherungen v. Atlarex), n. 405, IHR 2001, 72 mit Bezugnahmen auf 40 ausländische CISG-Entscheidungen; Trib. Rimini 26.11.2002 (Al Palazzo S.r.l. v. Bernardaud di Limoges S.A.), n. 3095 mit Bezugnahmen auf 32 ausländische CISG-Entscheidungen; Trib. Forli 11.12.2008 (Mitias v. Solidea S.r.l.), n. 2280/2007 mit Bezugnahmen auf 40 ausländische CISG-Entscheidungen. Kritisch zu diesen Schwenzer, IHR 2010, 45, 46: ,just a formalistic exercise“.

107 Dazu schon oben V.2. a) (1) (a).

${ }^{108}$ BGH 2.3.2005, NJW-RR 2005, 1218, 1219.

109 Delchi Carrier S.p.A. v. Rotorex Corp., 71 F.3d 1024, 1028 (2nd Cir. 1995).

${ }_{110}$ Vgl. etwa Raw Materials Inc. v. Manfred Forberich GmbH \& Co. KG, 2004 WL 1535839 (N.D. Ill.); Dingxi Longhai Diary, Ltd. v. Becwood Technology Group L.L.C., 635 F.3d 1106 (8th Cir. 2011).

111 Henry Gabriel, Contracts for the Sale of Goods² (2009) 64f.; Harry M. Flechtner, The CISG in American Courts: The Evolution (and Devolution) of the Methodology of Interpretation, in: Quo Vadis CISG, hrsg. von Franco Ferrari (2005) 91 ff.; Honnold/Flechtner, Uniform Law (Fn. 82) Rn. 92: ,[...] a line of cases incorporating what may be the most brazen flouting of those mandates [Art. 7(1) CISG] [...] "; Joseph Lookofsky/Harry M. Flechtner, Nominating Manfred Forberich: The Worst CISG Decision in 25 Years?, Vindobona J. of Int'l Commercial Law \& Arbitration 9 (2005) 199, $205 \mathrm{ff}$.

112 Schlechtriem/Schroeter, Int. UN-Kaufrecht (Fn. 29) Rn. 93. 
Konflikt geraten kann. Dies heißt allerdings nicht, dass US-amerikanische Gerichte niemals auf ausländische Urteile zum UN-Kaufrecht Bezug nehmen - positive Beispiele dieser Art gibt es durchaus. ${ }^{113}$

(c) Begrenzte Uneinheitlichkeiten in der Anwendung. - Fragt man nach Uneinheitlichkeiten in der praktischen Anwendung des Einheitskaufrechts und ihren Gründen, so müssen verschiedene Fallgruppen unterschieden werden. Manche scheinbare Uneinheitlichkeit geht tatsächlich auf Unterschiede in den Fakten zurück und nicht auf die Interpretation der angewandten Norm; Art. 7(1) CISG, dessen Vorgaben sich ausdrücklich nur auf den Vorgang der „Auslegung“ des Übereinkommens beziehen, ${ }^{114}$ ist hier gar nicht betroffen. Eine weitere Fallgruppe umfasst divergierende Ausgangspunkte in Interpretationsfragen, die letztlich jedoch in übereinstimmende Ergebnisse münden und die anzustrebende Einheitlichkeit der Anwendung daher nicht beeinträchtigen: Ein Beispiel betrifft die angemessene Rügefrist des Art. 39(1) CISG, die der BGH und das schweizerische Bundesgericht (BGer.) ausgehend von einer einmonatigen „Regelfrist" bestimmen wollen, ${ }^{115}$ während der österreichische OGH von einer vierzehntägigen Regelfrist ausgeht, die als Gesamtfrist zudem die nach Art. 38 CISG erforderliche Untersuchung und die Mängelrüge i.S.d. Art. 39(1) CISG umfassen soll. ${ }^{116}$ Vor diesem Hintergrund mag es überraschen, dass die Rechtsanwendungsergebnisse sich in vergleichbaren Fällen kaum unterscheiden, ${ }^{117}$ sodass das Auslegungsziel der einheitlichen Anwendung letztlich doch erreicht wird; die verschiedenen Höchstgerichte nähern sich diesem nur gleichsam aus verschiedenen Richtungen. ${ }^{118}$

Dass die rechtliche Bedeutung von UN-Kaufrechtsbestimmungen international uneinheitlich bestimmt wird, ist dagegen (bislang) selten. Divergierende Rechtsprechung besteht etwa zur Frage, ob die chinesische Sonderverwaltungsregion Hongkong seit dem Souveränitätsübergang von Großbritannien (Nichtvertragsstaat) auf die Volksrepublik China (CISG-

113 Medical Marketing International, Inc. v. Internazionale Medico Scientifica, S.r.l., 1999 W L 311945 (E.D. La.); Chicago Prime Packers, Inc. v. Northam Food Trading Co., 320 F.Supp. 2d 702 (N.D. Ill. 2004); Innotex Precision Limited v. Horei Image Products, Inc., 2009 U.S. Dist. LEXIS 117992 (N.D. Ga.).

${ }^{114}$ Eine Entwurfsfassung hatte diese auch auf die Anwendung des Übereinkommens bezogen, wurde jedoch geändert; vgl. United Nations Conference on Contracts for the International Sale of Goods, Vienna, 10 March - 11 April 1980: Official Records (1991) 87. A.A. (gleichwohl Geltung des Art. 7(1) CISG auch für die Übereinkommensanwendung) Honsell/ Melis (Fn. 103) Art. 7 Rn. 3.

115 BGH 3.11.1999 - VIII ZR 287/98, NJW-RR 2000, 1361, 1362; BGer. 13.11.2003 4C.198/2003, IHR 2004, 215, 217.

${ }_{116}$ OGH 15.10.1998 - 2 Ob 191/98x, JBl 1999, 318, 321; OGH 31.8.2010 - 4 Ob 98/10f, IHR 2011, 85, 88.

117 Ulrich Magnus, 25 Jahre UN-Kaufrecht, ZEuP 14 (2006) 96, 101; Posch, ZfRV 2014, 76, 79f.; Schlechtriem/Schroeter, Int. UN-Kaufrecht (Fn. 29) Rn. 413.

118 Posch, ZfRV 2014, 76, 79.

Schwerpunkt: Stand und Perspektiven des Einheitsrechts

\section{Digitaler Sonderdruck des Autors mit Genehmigung des Verlages}


Vertragsstaat) als Vertragsstaatenterritorium i. S.d. Art. 1, 89 ff. CISG anzusehen ist ${ }^{119}$ oder nicht. ${ }^{120}$ Da nicht nur Gerichte aus unterschiedlichen Vertragsstaaten, sondern sogar solche innerhalb ein und desselben Vertragsstaats (den USA) insoweit uneinheitlich entschieden haben, ${ }^{121}$ hindert hier wohl die Komplexität der Rechtsfrage die Einheitlichkeit. Vorhersehbar sind Abweichungen auch beim Umgang mit hardship-Fällen und der Rolle des Art. 79 CISG, weil ein einschlägiges belgisches Urteil ${ }^{122}$ berechtigterweise so scharfe Kritik ${ }^{123}$ erfahren hat, dass widersprechende Entscheidungen anderer Gerichte kaum überraschen würden.

(d) Streben nach Einheitlichkeit als dauerhafter, mehrphasiger Prozess. - Da trotz aller noch zu erörternder ${ }^{124}$ institutioneller Vorkehrungen damit gerechnet werden muss, dass es gelegentlich zu einer international uneinheitlichen Auslegung des Einheitskaufrechts kommen wird, spricht vieles dafür, die Verwirklichung des Einheitlichkeitsziels als Mehr-Phasen-Prozess zu betrachten: Das Auftreten von Auslegungsdivergenzen bedeutet danach nicht per se, dass die Beachtung des Art. 7(1) CISG gescheitert ist, sondern stellt in der Regel eine lediglich vorübergehende Phase der Uneinheitlichkeit dar, ${ }^{125}$ an die sich in einer weiteren Phase die Berücksichtigung abweichender ausländischer Rechtsprechung und gegebenenfalls die Anpassung der innerstaatlichen Auslegungslinie anschließen wird. Ein solcher Mehr-PhasenProzess ist schon deshalb wahrscheinlich, weil die noch zu thematisierende grenzüberschreitende Kooperation zwischen vertragsstaatlichen Gerichten zur Erreichung einer einheitlichen Auslegung ${ }^{126}$ vor allem durch die Höchstgerichte der einzelnen Vertragsstaaten verwirklicht werden wird. Ihnen ist die Sicherung der Einheitlichkeit der Rechtsprechung schließlich auch innerstaatlich zugewiesen, und sie verfügen zudem typischerweise über eine

119 Rechtbank van Koophandel Turnhout 18.1.2001 - A/00/691 (Index Syndicate Ltd. v. NV Carta Mundi); OLG Innsbruck 3.6.2003 - 1 R 90/03z-27; so auch Ulrich G. Schroeter, Die Vertragsstaateneigenschaft Hongkongs und Macaus unter dem UN-Kaufrecht, IHR 2004, 7, 9 ff.

${ }^{120}$ Cass. civ. $1^{\mathrm{e}}$ 2.4.2008, ${ }^{\circ}$ 04-17726; Hannaford (trading as Torrens Valley Orchards) v Australian Farmlink Pty Ltd [2008] FCA 1591 (obiter).

${ }^{121}$ Für Vertragsstaatenstatus Hongkongs CNA Int'l v. Guangdon Kelon Elec. Holdings, 2008 U.S. Dist. LEXIS 113433 (N.D. Ill.); Electrocraft Ark., Inc. v. Super Electric Motors, Ltd et al., 2009 WL 5181854 (E.D. Ark.); dagegen Innotex, 2009 U.S. Dist. LEXIS 117992 (N.D. Ga.); America's Collectibles Network, Inc. et al. v. Timlly (HK) et al., 746 F. Supp. 2 d 914 (E.D. Tenn. 2010).

122 Cass. 19.6.2009 - C.07.0289.N (Scafom International BV v. Lorraine Tubes S.A.S.).

123 Harry M. Flechtner, The Exemption Provisions of the Sales Convention, Belgrade L. Rev. 59:3 (2011) 84, 92 ff.; Schlechtriem/Schroeter, Int. UN-Kaufrecht (Fn. 29) Rn. 681; Anna Veneziano, UNIDROIT Principles and CISG: Change of Circumstances and Duty to Renegotiate according to the Belgian Supreme Court, Unif. L. Rev. 2010, 137, 144; positiver Staudinger/Magnus (Fn. 83) Art. 79 CISG Rn. 24.

${ }^{124}$ Unter V.2. b).

125 Ähnlich Neumann, Pace Int'l L. Rev. 27 (2015) 119, 127.

126 Dazu noch unten V.2. b) (2). 
geeignetere Ausstattung als Instanzgerichte, um ausländische Judikate zu ermitteln. ${ }^{127}$ So geht die in Deutschland heute einheitlich praktizierte, tolerante Interpretation des Art. 39(1) CISG im Sinne einer einmonatigen Regelfrist ${ }^{128}$ erst auf eine entsprechende BGH-Entscheidung ${ }^{129}$ zurück, mittels derer der BGH eine bis dahin unter deutschen Instanzgerichten verbreitete Auslegung korrigierte, die sich ersichtlich an der (strengeren) Frist des $\$ 377$ HGB orientiert hatte ${ }^{130}$ und daher einen ,homeward trend“ darstellte. ${ }^{131}$

Schließlich ist daran zu erinnern, dass uneinheitliche Rechtsauslegungen auch innerhalb nationaler Rechtsordnungen vorkommen ${ }^{132}$ - man denke für Deutschland nur an die jahrelangen „Kriege der Senate“ des BGH zur Frage der Sittenwidrigkeit von Angehörigenbürgschaften ${ }^{133}$ und zur widerrufsbedingten Rückabwicklung von Immobilienfondsbeteiligungen ${ }^{134}$ und auch dort nicht selten durch die divergierenden Spruchkörper selbst bereinigt werden, ohne dass hierfür eigentlich vorgesehene Lösungsmechanismen (etwa die Divergenzvorlage nach $\$ 132$ II, III GVG) genutzt würden. Entsprechende Situationen werden auf internationaler Ebene ebenfalls zu bewältigen sein, ohne dass die Verwirklichung der Ziele des Art.7(1) CISG hierdurch vereitelt würde.

\section{b) Institutionelle Rahmenbedingungen der Auslegung}

Von besonderem Interesse ist im Einheitsrecht seit jeher die Frage, ob die Sicherung einer international einheitlichen Auslegung einen bestimmten institutionellen Rahmen voraussetzt, und wie dieser gegebenenfalls beschaffen sein müsste. ${ }^{135}$ Die diesbezügliche Diskussion hat auch das Einheitskaufrecht von vornherein begleitet ${ }^{136}$ und dürfte sich auf absehbare Zeit fortsetzen.

127 Dies bedeutet nicht, dass die Vorgaben des Art. 7(1) CISG nicht auch durch Instanzgerichte beachtet werden sollten - es steht jedoch zu erwarten, dass dies in der Praxis lediglich in geringerem Maße möglich sein wird (vgl. etwa Kropholler, Int. Einheitsrecht (Fn. 8) 283: „Für die Untergerichte sind die Schwierigkeiten oft unüberwindlich“). Siehe zum rechtlichen Adressaten des Art. 7(1) CISG bereits oben Fn. 88.

128 Dazu bereits oben (c).

129 BGH 3.11.1999, NJW-RR 2000, 1361, 1362. Ein ,grober Mittelwert“ von einem Monat war zuvor schon in BGH 8.3.1995 - VIII ZR 159/94, BGHZ 129, 75, 85 f. genannt, damals aber noch als ,,nach Auffassung des erkennenden Senats sehr großzügig“ bezeichnet worden.

130 Vgl. die Nachweise bei Ingeborg Schwenzer, in: Schlechtriem/Schwenzer, Kommentar (Fn. 45) Art. 39 Rn. 17.

131 Schwenzer, IHR 2010, 45, 50.

132 Ebenso zum UCC Honnold, ITBLR 1 (1995) 1, 8.

133 Vgl. Stephan Lorenz, Richtlinienkonforme Auslegung, Mindestharmonisierung und der „Krieg der Senate“, NJW 1998, 2937 ff.

134 Vgl. Nikolaj Fischer, Direktvertrieb und Rückabwicklung kreditfinanzierter Fondsbeteiligungen und der „Krieg der Senate“, VuR 2005, $241 \mathrm{ff}$.

135 IECL/David (Fn. 51) Anm. 285 ff.

$136 \mathrm{Vgl}$. Ernst Rabel, Observations sur l'utilité d'une unification du droit de la vente au

Schwerpunkt: Stand und Perspektiven des Einheitsrechts

\section{Digitaler Sonderdruck des Autors mit Genehmigung des Verlages}


(1) Fehlen eines Obergerichts mit zentraler Auslegungszuständigkeit

Unter den denkbaren institutionellen Arrangements, durch die eine uniforme Einheitsrechtsinterpretation verwirklicht werden könnte (und ohne welche diese nach Ansicht mancher ${ }^{137}$ von vornherein unerreichbar ist), wird ein internationales Obergericht mit zentraler Auslegungszuständigkeit verbreitet als Königsweg angesehen. ${ }^{138}$ Freilich ist die Schaffung eines solchen Gerichts mit globalem geographischem Zuständigkeitszuschnitt unrealistisch, ${ }^{139}$ und auch die bereits versuchte Nutzung des Internationalen Gerichtshofs (IGH) zu einem solchen Zweck (etwa durch Art. 47 CMR) schlug praktisch fehl. ${ }^{140}$ Gegen die häufig vorgeschlagene Übertragung einer Auslegungskompetenz auf den Europäischen Gerichtshof $(\mathrm{EuGH})^{141}$ sprechen schließlich zwei Gründe: Zum einen wäre eine regionalisierte („europäische") Interpretation des Einheitskaufrechts die wohl unvermeidliche Folge, die aber gegen die auf globale Einheitlichkeit zielenden Vorgaben des Art. 7(1) CISG verstieße. ${ }^{142}$ Zum anderen - und dies dürfte entscheidend sein - würde ein Vorlageverfahren zum EuGH die gerichtliche Streitbeilegung bei CISG-Verträgen in einer Weise zeitlich verzögern, die im internationalen Handelsverkehr kaum hinnehmbar erscheint. ${ }^{143}$ Erfolgreiche Vorlageanregungen taktierender Beklagter drohten daher auf einen „Luxemburg-Torpedo“"144 hinauszulaufen, der ein noch stärkeres Abwandern in die Schiedsgerichtsbarkeit ${ }^{145}$ nach sich zöge.

point de vue des besoins du commerce international, RabelsZ 22 (1957) 117, 123 (Neuabdruck eines Beitrags aus dem Jahre 1929); zum Haager Kaufrecht R.H. Graveson/E.J. Cohn/ Diana Graveson, The Uniform Laws on International Sales Act 1967 (1968) 5; zum UN-Kaufrecht Ulrich G. Schroeter, UN-Kaufrecht und Europäisches Gemeinschaftsrecht: Verhältnis und Wechselwirkungen (2005) $\$ 21$ Rn. 8 ff. m.w.Nachw.

137 Haimo Schack, Internationales Zivilverfahrensrecht ${ }^{6}$ (2014) Rn. 90: „Geburtsfehler“; Rolf Schütze, Die Bedeutung des Wiener Kaufrechtsübereinkommens für das internationale Zivilprozeßrecht, in: FS Franz Matscher (1993) 423, 430.

138 So schon früh Peter Klein, Internationale Gerichtsbarkeit für das Gebiet des Weltwechselrechts, NiemZ 1914, 112, 114 ff.; später Otto Riese, Einheitliche Gerichtsbarkeit für vereinheitlichtes Recht, RabelsZ 26 (1961) 604ff.; aus neuerer Zeit Kropholler, Int. Einheitsrecht (Fn. 8) 144ff.; Posch, ZfRV 2014, 76, 80; Sheaffer, Cardozo J. Int'l \& Comp. L. 15 (2007) 461, 483. Zurückhaltender Rabel, Recht des Warenkaufs (Fn. 5) 48.

139 Bianca/Bonell/Bonell (Fn. 83) Art. 7 Anm.3.1.1; Schroeter, UN-Kaufrecht (Fn. 136) \21 Rn. 9 .

${ }^{140}$ Helga Jesser-Huß, in: Münchener Kommentar zum $\mathrm{HGB}^{3}$ (2014) Art. 47 CMR Rn. 1.

${ }^{141}$ Jürgen Basedow, Europäisches Privatrecht: Das UN-Kaufrecht vor den EuGH!, EuZW 1992, 489; Ulrich Drobnig, Ein Vertragsrecht für Europa, in: FS Ernst Steindorff (1990) 1141, 1145; Helmut Heiss, Europäisches Vertragsrecht: in statu nascendi?, ZfRV 1995, 54, 58; Ziegel, N.Z. Bus. L.Q. 6 (2000) 336, 346.

${ }_{142}$ Schroeter, UN-Kaufrecht (Fn. 136) $\$ 20$ Rn. 11 ff., $\$ 21$ Rn. 46.

143 So auch Honnold, ITBLR 1 (1995) $1,8$.

144 Schlechtriem/Schroeter, Int. UN-Kaufrecht (Fn. 29) Rn. 99.

${ }^{145}$ Siehe dazu noch unter V.5. 
(2) Kooperation zwischen vertragsstaatlichen Gerichten

Ein realistischerer Ansatz liegt daher in einer informellen grenzüberschreitenden Kooperation vertragsstaatlicher Gerichte. ${ }^{146}$ Sie dürfte zugleich das Spannungsfeld zwischen der Förderung einer einheitlichen Übereinkommensinterpretation (Art. 7(1) CISG), die im Interesse der globalen Gesamtheit von Warenhändlern und Rechtsanwendern liegt, und der zügigen Streitentscheidung im Interesse der konkret betroffenen Streitparteien ausgewogener auflösen als ein formalisiertes und zeitaufwändiges Vorlageverfahren. Eine entsprechende Kooperation wird in Ansätzen bereits praktiziert, ${ }^{147}$ stößt jedoch auf die Herausforderung, dass sie dezentral und eigeninitiativ eingeleitet und perpetuiert werden muss; die zum UN-Kaufrecht judizierenden Gerichte sind daher treffend mit den Mitgliedern eines Orchesters ohne Dirigent ${ }^{148}$ verglichen worden.

Im Ergebnis wird, wie bereits angesprochen,${ }^{149}$ die grenzüberschreitende Kooperation vorrangig eine Aufgabe der Höchstgerichte der verschiedenen Vertragsstaaten sein, welche die ausländische Rechtsprechung zum Einheitskaufrecht beachten und dadurch dem Ziel seiner international einheitlichen Anwendung Rechnung tragen sollten. Dies setzt ihre Bereitschaft voraus, einschlägige Urteile aus anderen Staaten auch und gerade dann als mögliche persuasive authority in Betracht zu ziehen, wenn die darin vorgenommene Auslegung des UN-Kaufrechts von den bisherigen eigenen oder untergerichtlichen Auslegungsansätzen im Heimatstaat abweicht. In die instanzgerichtliche Rechtsprechung findet die einheitliche Interpretation so vorrangig mittels der innerstaatlichen Leitwirkung höchstrichterlicher Urteile Eingang, wobei es den Zielen des Art. 7(1) CISG sicherlich noch besser entspräche, wenn auch Instanzgerichte unmittelbar ausländische Einheitsrechtsinterpretationen berücksichtigen würden - freilich erscheint dies als nur bedingt realistisch. Angesichts des potentiell beträchtlichen Zeitaufwands, der mit Recherchen zu ausländischer Rechtsprechung und gegebenenfalls Literatur zum Einheitskaufrecht verbunden ist, ${ }^{150}$ dürfte die höchstwie instanzgerichtliche Judikatur jedenfalls Unterstützung benötigen, auf die im Folgenden einzugehen ist.

146 Camilla Baasch Andersen, The Uniform International Sales Law and the Global Jurisconsultorium, J.L. \& Com. 24 (2005) 159.

147 Oben V.2. a) (2) (b).

148 Peter Schlechtriem, Einheitskaufrecht in der Rechtsprechung des Bundesgerichtshofs, in: FS 50 Jahre BGH, Bd. I (2000) 407, 408.

149 Oben V.2. a) (2) (d).

150 Neumann, Pace Int'l L. Rev. 27 (2015) 119, 135. 
(3) Unterstützende Maßnahmen UNCITRALs

Schon vor Inkrafttreten des UN-Kaufrechts war innerhalb UNCITRALs das Bedürfnis erkannt worden, die internationale Zugänglichkeit von Urteilen und Schiedssprüchen zum Einheitskaufrecht zu ermöglichen oder zumindest zu verbessern. UNCITRAL selbst hat durch sein Sekretariat insoweit zwei Maßnahmen implementiert: Im Rahmen von CLOUT (Case Law On UNCITRAL Texts) erstellen nationale Korrespondenten kurze Zusammenfassungen (Abstracts) zu Entscheidungen zum UN-Kaufrecht, die sodann in die sechs UN-Amtssprachen übersetzt und veröffentlicht werden. CLOUT erleichtert so den Zugang zu ausländischer Rechtsprechung, indem es namentlich sprachliche Hürden reduziert, umfasst aber nicht den Volltext der betreffenden Entscheidungen. Letzterer Umstand beschränkt den Nutzen der bereitgestellten Informationen für den Rechtsanwender, der so zwar auf einschlägige Rechtsprechung hingewiesen wird, in der Regel aber auf eine Kenntnis der vollständigen Urteilsgründe und des zugrunde liegenden Sachverhalts angewiesen ist, um die Überzeugungskraft der in concreto erfolgten Übereinkommensinterpretation einschätzen zu können. Seit 2008 veröffentlicht UNCITRAL zudem einen sog. Case Digest, der die vorhandene Rechtsprechung hilfreich den ausgelegten CISG-Vorschriften zuordnet und in mehrjährigem Abstand aktualisiert wird.

Weitergehende, nicht lediglich informierende Maßnahmen zur Ermöglichung einer uniformen Einheitsrechtsinterpretation werden dagegen durch die der Neutralität verpflichtete Stellung UNCITRALs ${ }^{151}$ und den Umstand ausgeschlossen, dass der Übereinkommenstext UNCITRAL insofern keine Rolle zuweist, sondern die Auslegungs- und Anwendungsaufgabe (implizit) den nationalen Gerichten überlässt. Damit übereinstimmend hat UNCITRAL eigene Stellungnahmen zu Auslegungsdivergenzen schon früh ausgeschlossen, ${ }^{152}$ und auch die vorgeschlagene Schaffung eines „Permanent Editorial Board“ zum UN-Kaufrecht, das die jeweils vorzugswürdige Auslegung vorschlagen könnte, ${ }^{153}$ wurde abgelehnt. ${ }^{154}$ Offizielle Maßnahmen UNCITRALs sammeln und publizieren daher die Einheitsrechtspraxis, ohne jedoch best practices zu identifizieren.

151 Vgl. zum UNCITRAL Case Digest Lookofsky, Vindobona J. of Int'l Commercial Law \& Arbitration 8 (2004) 181, 193.

${ }^{152}$ UNCITRAL Yearbook XVI (1985) 387, 389 Nr. $10 \mathrm{ff}$.

153 Michael J. Bonell, A Proposal for the Establishment of a „Permanent Editorial Board“ for the Vienna Sales Convention, in: International Uniform Law in Practice, hrsg. von UNIDROIT (1988) 241, 243. Siehe zu advisory opinions zur Einheitsrechtsauslegung im Übrigen auch IECL/David (Fn. 51) Anm. $297 \mathrm{ff}$.

${ }^{154}$ UNCITRAL Yearbook XIX (1988) 16 Nr. $107 \mathrm{ff}$.

Schwerpunkt: Stand und Perspektiven des Einheitsrechts

\section{Digitaler Sonderdruck des Autors mit Genehmigung des Verlages}


(4) Die Mittlerrolle der Wissenschaft

in grenzüberschreitender Kooperation

Den beschriebenen Grenzen unterliegt die internationale Wissenschaft nicht, weshalb ihr zur Erreichung der Ziele des Art. 7(1) CISG eine entscheidende Rolle zukommt. Zur Kooperation der Gerichte ${ }^{155}$ muss folglich eine akademische Kooperation hinzutreten, welche die einheitliche Rechtsanwendung in mehrerer Hinsicht erleichtern oder erst ermöglichen kann. Trotz ihrer primär technischen Natur unverzichtbar ist zunächst die Erfassung, Übersetzung und Zugänglichmachung des Volltextes zum UN-Kaufrecht ergangener Urteile, die das auf Abstracts beschränkte CLOUT-System UNCITRALs ${ }^{156}$ in sinnvoller Weise ergänzt. Die effektive Verbreitung des so aufgearbeiteten Rechtsprechungsmaterials wurde im Grunde erst durch das Internet möglich, dessen private Nutzung praktisch zeitgleich mit den ersten Urteilen zum UN-Kaufrecht begann - damit entfielen die viel beklagten praktischen Hindernisse, die bis dahin dem Zugang zur nur in gedruckter Form verfügbaren Einheitsrechtspraxis entgegengestanden hatten. ${ }^{157}$ Von Universitäten betriebene, kostenfrei nutzbare Internet-Datenbanken ${ }^{158}$ sind daher heute die weltweit führenden Informationsquellen zum Einheitskaufrecht, über die zudem einschlägiges Schrifttum im Volltext zugänglich gemacht wird.

Mit der wachsenden Zahl von Gerichtsentscheidungen zum UN-Kaufrecht ist darüber hinaus die systematische Ordnung und kritische Bewertung der internationalen Einheitsrechtspraxis unverzichtbar geworden, die der einzelne Rechtsanwender kaum leisten kann. Auch hier ist die Wissenschaft aufgerufen, ${ }^{159}$ die nicht den strengen Neutralitätsschranken UNCITRALs unterliegt und daher auch kritikwürdige Rechtsprechungsbeispiele zu identifizieren vermag. Kommentare deutscher Tradition (article-by-article commentaries) haben sich als besonders erfolgreiches Medium zur Erfüllung dieser Aufgabe erwiesen, das zunehmend auch außerhalb des deutschen Sprachraums Verwendung findet.

In institutionalisierter Form findet eine wissenschaftliche Kooperation seit 2001 im Rahmen des CISG Advisory Council (CISG-AC) ${ }^{160}$ statt. Dieser private Zusammenschluss zum UN-Kaufrecht forschender Wissenschaftler

155 Oben (2).

156 Oben (3).

157 Siehe Kropholler, Int. Einheitsrecht (Fn. 8) 284 f.

158 Namentlich die Albert H. Kritzer Database der Pace Law School und die Datenbank CISG online der Universität Basel (zu beiden oben Fn. 67).

159 Bridge, International Sale (Fn. 22) Rn. 10.39; Posch, ZfRV 2014, 76, 78.

160 Der Autor der vorliegenden Abhandlung ist seit 2013 Mitglied des CISG-AC, <www. cisg-ac.org>. Siehe zum CISG-AC näher Rolf Herber, Eine neue Institution: Der CISG Advisory Council, IHR 2003, $201 \mathrm{f}$; Ingeborg Schwenzer, The CISG Advisory Council, NTHR 2012, $46 \mathrm{ff}$.

Schwerpunkt: Stand und Perspektiven des Einheitsrechts

\section{Digitaler Sonderdruck des Autors mit Genehmigung des Verlages}


erarbeitet und veröffentlicht Stellungnahmen (Opinions) zu klärungsbedürftigen Auslegungsfragen, die von Gerichten als persuasive authority herangezogen werden können ${ }^{161}$ und dadurch zur einheitlichen Interpretation des Einheitskaufrechts beitragen. ${ }^{162}$ Insbesondere die niederländische Rechtsprechung verwendet Opinions des CISG-AC seit einiger Zeit geradezu routinemäßig als Auslegungsleitlinie. ${ }^{163} \mathrm{Da}$ es sich um ein privates Gremium ohne offizielles Mandat zur authentischen Interpretation des Übereinkommens handelt, beruht die persuasive authority seiner bislang 17 publizierten Stellungnahmen ${ }^{164}$ auf der Fachkunde seiner Mitglieder und Berichterstatter sowie - vor allem - der Überzeugungskraft der einzelnen Auslegungsvorschläge. ${ }^{165}$ Als vorteilhaft erweist sich dabei die internationale Zusammensetzung des CISG-AC, infolge derer stets durch unterschiedliche regionale und rechtskulturelle Hintergründe geprägte Sichtweisen in die Diskussion von Opinion-Entwürfen Eingang finden. Zudem verfügt die private Wissenschaftlergruppe über die Freiheit, proaktiv klärungsbedürftige Interpretationsfragen aufzugreifen und dadurch bereits dem Entstehen oder jedenfalls der Verfestigung sich andeutender Auslegungsdivergenzen entgegenzuwirken, ohne dabei einem primär in politischen Erwägungen gründenden Neutralitätszwang ${ }^{166}$ zu unterliegen.

\section{c) Verfahrensrechtliche Umsetzung der Vorgaben des Art. 7(1) CISG}

Kaum erörtert worden ist bislang, in welcher Weise die in Art. 7(1) CISG auf zwischenstaatlicher Ebene angeordneten Auslegungsziele auf Ebene des innerstaatlichen Prozessrechts umzusetzen sind und welche Pflichten der Prozessbeteiligten (Gerichte, Prozessparteien, Prozessbevollmächtigte) sich unmittelbar oder mittelbar aus Art. 7(1) CISG ableiten lassen.

161 So etwa TeeVee Toons, 2006 WL 2463537 (S.D.N.Y.); Sad Najwyzszy (Oberstes Gericht Polen) 11.5.2007 - V CSK 456/06 (Spoldzielnia Pracy „A“ v. M.W.D. GmbH E Co. KG); beiläufig auch BGH 28.5.2014 - VIII ZR 410/12, NJW-RR 2014, 1202, 1204; BGH 24.9. 2014 - VIII ZR 394/12, BGHZ 202, 258 Tz. 28.

162 Staudinger/Magnus (Fn. 83) Art. 7 CISG Rn. 23a.

163 Statt vieler: Parket bij de Hoge Raad 15.1.2016 - 14/06070 (Integrated Logistics Co.); Gerechtshof Arnhem 9.3.2010 (Pastificio Della Mamma S.A.); Gerechtshof Den Haag 22.4.2014 (Feinbäckerei Otten GmbH v Rhumfeld Winter B.V.); Gerechtshof 's-Hertogenbosch 29.9.2015 (Gebrüder X GmbH \& Co. KG v Machine-en Transportwerktuigenfabriek Y B.V.), NTHR 2015, 317.

$164 \mathrm{Zu}$ dieser auch Oliver Remien, Funktion der Wissenschaft bei der Identifikation des Internationalen Privat- und Handelsrechts, in: Freiheit und Regulierung in der Cyberwelt Rechtsidentifikation zwischen Quelle und Gericht, hrsg. von Nina Dethloff/Georg Nolte/ August Reinisch (2016) 241, 261: „,mehr Herausforderung als Status“.

165 Schlechtriem/Schroeter, Int. UN-Kaufrecht (Fn. 29) Rn. 98.

166 Siehe zur aus diesem Grund erfolgten Ablehnung der Schaffung eines „Permanent Editorial Board“ im Rahmen UNCITRALs bereits oben (3). 
In der Praxis ist vor allem in Verfahren vor common law-Gerichten relevant geworden, ob staatliche Richter in CISG-Vertragsstaaten das UN-Kaufrecht von Amts wegen zur Anwendung bringen müssen oder nur dann, wenn sich die Prozessparteien darauf berufen haben. An Letzterem fehlt es in der Praxis nicht selten, wenn Parteien und ihre Prozessbevollmächtigten sich der Anwendbarkeit des Übereinkommens gar nicht bewusst sind - ein Umstand, der die Prozessbevollmächtigten dem Risiko einer anwaltlichen Haftung aussetzt, weil Rechtsanwälten das anwendbare materielle Recht nach den Pflichtenmaßstäben der meisten Rechtsordnungen bekannt sein muss oder sie sich eine solche Kenntnis rechtzeitig verschaffen müssen. ${ }^{167}$ In Jurisdiktionen, in denen der Grundsatz iura novit curia gilt, führt schon dieser zu einer Anwendungspflicht des staatlichen Richters, der ahnungslose Prozessbeteiligte zudem nach $\$ 139$ ZPO (oder funktionsäquivalenten Normen) auf die Anwendbarkeit des UN-Kaufrechts hinweisen muss. ${ }^{168}$ In anderen Jurisdiktionen stellt sich dagegen die Frage, ob die im Übereinkommen selbst angelegte Pflicht vertragsstaatlicher Richter zu dessen Anwendung ${ }^{169}$ nur vorbehaltlich oder aber ungeachtet verfahrensrechtlicher Geltendmachungserfordernisse gilt, ${ }^{170}$ welche das UN-Kaufrecht in der Sache zu einem „fakultativen“ Einheitsrecht ${ }^{171}$ machen. Einen im letztgenannten Sinne unbedingten Anwendungsanspruch des Übereinkommens wird man kaum annehmen können, weil dieser sich nicht nur an den Vertragsstaat als Übereinkommenspartei richten, sondern kraft stillschweigender Anordnung gleichsam in dessen innerstaatliche Verfahrensorganisation „hineinreichen“ würde; dies wäre für privatrechtsvereinheitlichende Staatsverträge ungewöhnlich. Ein so verstandener völkervertraglicher Anwendungsbefehl geriete zudem mit austarierten prozessrechtlichen Regeln über den Zeitpunkt in Konflikt, bis zu welchem Prozessparteien sich auf anwendbares materielles Recht berufen haben müssen; schließlich droht eine judikative Ausweichbewegung hin zur häufigeren Annahme eines impliziten Übereinkom-

167 Zum deutschen Recht Martin Henssler, Haftungsrisiken anwaltlicher Tätigkeit, JZ 1994, 178, 185; zum US-amerikanischen Recht Ronald A. Brand, Uni-State Lawyers and Multinational Practice: Dealing with International, Transnational, and Foreign Law, Vanderbilt J. Transnat'l L. 34 (2001) 1135, 1163; zu beidem Schroeter, Empirical Evidence (Fn. 60) 649, $664 \mathrm{f}$.

${ }^{168}$ So zu $\$ 182$ a österr. ZPO OGH 2.4.2009 - 8 Ob 125/08b, IHR 2009, 246, 249; Schlechtriem/Schroeter, Int. UN-Kaufrecht (Fn. 29) Rn. 58.

${ }^{169} \mathrm{Vgl}$. die treffende Formulierung bei Honnold/Flechtner, Uniform Law (Fn. 82) Rn. 103.2: ,[...] the commitment that Contracting States make to each other: We will apply these uniform rules in place of our own domestic law on the assumption that you will do the same."

${ }^{170}$ In letztgenanntem Sinne Lisa Spagnolo, CISG Exclusion and Legal Efficiency (2014) $285 \mathrm{ff}$.

${ }^{171}$ Zum Vorschlag eines lediglich fakultativen Kollisionsrechts Axel Flessner, Fakultatives Kollisionsrecht, RabelsZ 34 (1970) 547; a. A. statt vieler BGH 7.4.1993 - XII ZR 266/91, NJW 1993, 2305; Jan Kropholler, Internationales Privatrecht ${ }^{6}$ (2006) \$ 7 II 2. 
mensausschlusses durch Prozessverhalten, den Art. 6 CISG grundsätzlich zulässt. Die besseren Gründe sprechen nach alledem dafür, den angesprochenen Anwendungsaspekt den nationalen Verfahrensrechten zu überlassen.

Regelungen des innerstaatlichen Prozess-, Anwaltsvertrags- und gegebenenfalls Berufsrechts bestimmen sodann auch darüber, ob und in welchen Grenzen den Prozessbevollmächtigten eine Pflicht zur Ermittlung und zum Vortrag ausländischer Rechtsprechung zum UN-Kaufrecht ${ }^{172}$ trifft, die den Rechtsstandpunkt seines Mandanten unterstützt. Nach deutschem Prozessrecht gehört die Ermittlung ausländischer Präjudizien zum uneingeschränkten Aufgabenbereich des Richters; die Ermessensbestimmung des $\$ 293$ ZPO soll keine Anwendung finden, weil es nicht um die Ermittlung ausländischen, sondern die Interpretation inländischen Rechts gehe. ${ }^{173}$ Angesichts der strengen deutschen Rechtsprechung zu Anwaltspflichten ${ }^{174}$ wird man gleichwohl eine ergänzende Vortragspflicht des Prozessbevollmächtigten anzunehmen haben, ${ }^{175}$ die sich in ihrer Reichweite aber auf solche ausländischen Präjudizien beschränken sollte, die dem Prozessbevollmächtigten in zumutbarer Weise (insbesondere gegebenenfalls in eine ihm verständliche Sprache übersetzt) zugänglich sind. Eine richterliche Nichtbeachtung von Art. 7(1) CISG stellt sodann einen materiellen Revisionsgrund dar, weil sich die Frage, ob eine Gesetzesverletzung vorliegt, nur anhand dieser Bestimmung entscheiden lässt ( $\left.\$ \int 545 \mathrm{I}, 546 \mathrm{ZPO}\right) .{ }^{176}$

Weder aus Art.7(1) CISG noch aus allgemeinen völkervertraglichen Grundsätzen wird man schließlich eine Pflicht von Vertragsstaaten ableiten können, ihre Gerichtsstruktur in einer der uniformen Einheitsrechtsanwendung dienenden Weise auszugestalten, indem etwa spezialisierte Spruchkörper mit besonderer Zuständigkeit (auch) für das Einheitskaufrecht geschaffen werden. Freilich wäre ein solcher Schritt besonders hilfreich, ${ }^{177}$ denn gerade die nur seltene, eher zufällige Befassung der meisten Richter mit dem UN-Kaufrecht erschwert dessen einheitliche Auslegung, weil sich so keine Erfahrung in der Bewältigung der besonderen Anforderungen von Art. 7(1) CISG ansammeln kann. Man wird insoweit aber auf entsprechende Initiativen der nationalen Gesetzgeber hoffen müssen.

${ }^{172}$ Zur Berücksichtigung ausländischer Judikate im Rahmen von Art. 7(1) CISG bereits oben V.2. a) (1) (b) und (2) (b).

173 Witz/Salger/Lorenz/Witz (Fn. 91) Art. 7 Rn. 9 (der aber eine analoge Anwendung des $\$ 293$ ZPO erwägt, soweit die Beschaffung ausländischer Präjudizien in Rede steht).

${ }^{174}$ Vgl. jüngst BGH 10.12.2015 - IX ZR 272/14, NJW 2016, 957, 958: Verpflichtung des Rechtsanwalts, ,das Rechtsdickicht zu lichten“.

175 Schroeter, Empirical Evidence (Fn.60) 667; ähnlich zum US-amerikanischen Recht Brand, Vanderbilt J. Transnat'l L. 34 (2001) 1135, 1163.

176 Witz/Salger/Lorenz/Witz (Fn. 91) Art. 7 Rn. 1.

177 Kropholler, Int. Einheitsrecht (Fn. 8) $135 \mathrm{ff}$. 
3. Abgrenzung des Anwendungsbereiches des Einheitskaufrechts

Die Vorgaben des Art. 7(1) CISG gelten auch für die Präzisierung des sachlich begrenzten Anwendungsbereiches des Einheitskaufrechts (vielfach auch - sprachlich unschön - bezeichnet als Ermittlung ,externer Lücken“"178), die stets zugleich dessen Abgrenzung gegenüber dem subsidiär anwendbaren nationalen Recht bedeutet. Die Bestimmung des Verhältnisses zwischen konkurrierenden Rechtsinstituten ist auch innerhalb nationaler Rechtsordnungen nötig - man denke nur an das Verhältnis zwischen Sachmängelgewährleistung und Irrtumsanfechtung, das bekanntlich selbst unter den deutschsprachigen Rechtsordnungen ganz unterschiedlich gesehen wird; ${ }^{179}$ sie stellt sich als Aufgabe im Fall des Einheitskaufrechts jedoch gleichsam multipliziert, weil dessen Regeln gegenüber Funktionsäquivalenten aus 85 Vertragsstaaten sowie potentiell noch weiterer (nicht-vertragsstaatlicher) Rechtsordnungen abzugrenzen sein können. Entsprechend vielgestaltig ist das Fallmaterial.

In methodischer Hinsicht empfiehlt es sich hier, im Sinne einer zweigliedrigen Abgrenzungsformel ${ }^{180}$ danach zu fragen, ob eine nationale Regelung sowohl denselben Sachverhalt erfasst als auch denselben Regelungsgegenstand betrifft wie das UN-Kaufrecht - ist beides zu bejahen, so wird sie durch das Übereinkommen verdrängt. Insoweit ist mit Blick auf „klassische" Konkurrenzfragen entschieden worden, dass der Anwendungsbereich des Einheitskaufrechts sowohl die in civil law-Rechtsordnungen vorgesehene Anfechtung wegen Käuferirrtums über Eigenschaften der Ware ${ }^{181}$ als auch das consideration-Erfordernis ${ }^{182}$ und die parol evidence rule ${ }^{183}$ aus common lawJurisdiktionen überlagert. Schwierigkeiten macht der Umgang mit Vertriebshändlerverträgen und anderen sachlich umfassenderen (Rahmen-) Vertragswerken, die wohl nur dann einem Kaufvertrag i.S.d. Art. 1 CISG ähneln und dem Übereinkommen unterstellt werden können, wenn sie be-

178 Vgl. Schlechtriem/Schwenzer/Ferrari (Fn. 45) Art. 7 Rn. 43; Schlechtriem/Schroeter, Int. UN-Kaufrecht (Fn. 29) Rn. 147.

${ }^{179}$ Hierzu knapp Schlechtriem/Schroeter, Int. UN-Kaufrecht (Fn. 29) Rn. 171.

180 Schlechtriem/Schroeter, Int. UN-Kaufrecht (Fn. 29) Rn. 124 ff.; Ulrich G. Schroeter, Defining the Borders of Uniform International Contract Law: The CISG and Remedies for Innocent, Negligent or Fraudulent Misrepresentation, Vill. L. Rev. 58 (2013) 553, 563 ff.; zustimmend Schlechtriem/Schwenzer/Schwenzer/Hachem (Fn. 79) Art. 4 Rn. 29.

181 Oberster Gerichtshof Israel 17.3.2009, [2009] IsrLR 27 Tz. 54; LG Aachen 14.5.1993 - 43 O 136/92, RIW 1993, 760, 761.

182 Norfolk Southern Railway Company v. Power Source Supply, Inc., 2008 U.S. Dist. LEXIS 56942 (W.D. Pa.); Ulrich G. Schroeter, in: Schlechtriem/Schwenzer, Kommentar (Fn. 45) Art. 29 Rn. 4.

${ }_{183}$ MCC-Marble Ceramic Center, Inc. v. Ceramica Nuova D'Agostino, S.p.A., 114 F.3d 1384 (11th Cir. 1998); hierzu CISG-AC Opinion Nr. 3 (Rapporteur: Hyland), IHR 2005, 81 Tz. $2.1 \mathrm{ff}$. 
reits Pflichten zur Abnahme und Zahlung bzw. zur Lieferung begründen. ${ }^{184}$ Auch in diesem Fall passen die Regelungen des UN-Kaufrechts für viele kaufrechtsfremde Pflichteninhalte (Wettbewerbsverbote, Kooperationspflichten u.Ä.) und deren Verletzung freilich nur bedingt, weil sie mit Blick auf Austauschverträge und nicht für Dauerschuldverhältnisse konzipiert wurden. In jüngerer Zeit geraten vermehrt auch anwendungsbereichsbezogene Fragestellungen in den Blick, die bei Schaffung des Einheitskaufrechts wohl gar nicht bedacht wurden. Hierzu zählen etwa die Ersatzfähigkeit von Rechtsverfolgungskosten nach dem Übereinkommen ${ }^{185}$ oder das Verhältnis von Art. 78 CISG zu nationalen post-judgment interest-Regelungen. ${ }^{186}$ Der Umgang mit Regelungsgegenständen dieser Kategorie dürfte in Zukunft im Vordergrund stehen.

\section{Lückenfüllung}

Ebenso wie andere einheitsrechtliche Übereinkommen hält auch das UN-Kaufrecht nicht für jede Rechtsfrage, die innerhalb seines sachlichen Regelungsbereichs relevant werden kann, eine ausdrückliche Antwort bereit. Um gleichwohl einen sofortigen Rückgriff auf unvereinheitlichtes nationales Recht zu vermeiden, sieht Art. 7(2) CISG ein zweistufiges Verfahren zur Füllung entsprechender ,interner Lücken“vor: Danach sind Fragen, die im UN-Kaufrecht geregelte Gegenstände betreffen, aber im Übereinkommen nicht ausdrücklich entschieden werden, vorrangig nach den allgemeinen Grundsätzen zu entscheiden, die dem Übereinkommen zugrunde liegen. Nur wo solche Grundsätze fehlen, gelangt das (regelmäßig nationale) Kauf- und Vertragsrecht zur Anwendung, das vom Kollisionsrecht der lex fori berufen wird; im Rahmen letzterer Anknüpfung kann etwa auch das unverändert geltende Haager IPR-Übereinkommen von $1955^{187}$ zum Tragen kommen und so ein Zusammenspiel von materiell- und kollisionsrechtlichem Einheitskaufrecht bewirken. ${ }^{188}$

${ }^{184}$ Multi-Juice, S.A. v. Snapple Beverage Corp., 2006 WL 1519981 (S.D.N.Y.); Viva Vino Import Corp. v. Farnese Vini, 2000 U.S. Dist. LEXIS 12347 (E.D. Pa.); Schlechtriem/Schroeter, Int. UN-Kaufrecht (Fn.29) Rn.62; Staudinger/Magnus (Fn.83) Art. 1 CISG Rn. $37 \mathrm{ff}$. Manche Gerichte gelangen dagegen großzügiger zur Anwendbarkeit des UN-Kaufrechts; vgl. etwa Cass. 14.12.1999, no. 895, Giust. civ. 2000, 2333; siehe auch OLG München 22.9. 1995 - 23 U 3750/95, RIW 1996, 1035.

185 Zapata Hermanos Sucesores, S.A. v. Hearthside Baking Company, Inc., 313 F.3d 385 (7th Cir. 2002).

${ }^{186}$ Vgl. dazu John Gotanda, Conflict of Interest: Article 78 CISG and Post-Judgment Interest Statutes, in: FS Ingeborg Schwenzer (2011) 600, 604ff.; a. A. (nach Regelungszweck differenzierend) Schlechtriem/Schroeter, Int. UN-Kaufrecht (Fn. 29) Rn. 749.

187 Oben Fn. 12.

188 Siehe zur möglichen Konkurrenzlage zwischen beiden Übereinkommen noch VIII.1.

Schwerpunkt: Stand und Perspektiven des Einheitsrechts

\section{Digitaler Sonderdruck des Autors mit Genehmigung des Verlages}


Die vorrangige Anwendung allgemeiner Grundsätze, die Art. 7(2) CISG anordnet und die in vergleichbarer Form mittlerweile in zahlreichen einheitsrechtlichen Übereinkommen vorgesehen ist, ${ }^{189}$ hat sich bewährt und einheitssichernde Wirkung gehabt. Dabei ist es nicht immer einfach, entsprechende übereinkommensimmanente Grundsätze zu identifizieren und überzeugend zu begründen; so dürfte eine allgemeine Kooperations- und Informationspflicht der Parteien, die der BGH apodiktisch bejaht, ${ }^{190}$ dem UN-Kaufrecht kaum zu entnehmen sein. ${ }^{191}$ Zurückhaltung ist auch dort geboten, wo eine Ableitung allgemeiner Grundsätze aus vertragsrechtlichen Prinzipienwerken wie namentlich den UNIDROIT Principles of International Commercial Contracts in Rede steht: Art.7(2) CISG beruft ausdrücklich nur solche Grundsätze, die dem UN-Kaufrecht selbst zugrunde liegen, ${ }^{192}$ was auch bei rechtsvergleichend erarbeiteten soft law-Grundregeln keineswegs pauschal unterstellt werden kann, sondern jeweils zu belegen wäre. ${ }^{193} \mathrm{Häu-}$ fig wird die lückenfüllende Anwendung entsprechender soft laws selbst näherliegen, für die freilich eine kollisionsrechtliche Grundlage in der einschlägigen lex fori bzw. lex arbitri bestehen muss.

Mittels der zweistufigen Vorgehensweise des Art. 7(2) CISG sind in der bisherigen Übereinkommenspraxis verschiedene Lücken auf der ersten oder der zweiten Stufe gefüllt worden. So fehlen im UN-Kaufrecht insbesondere ausdrückliche Regelungen $\mathrm{zu}$ manchen Fragestellungen des allgemeinen Schuldrechts, von denen einige - wie etwa die Behandlung von Stellvertretungen oder Abtretungen - nach wohl einhelliger Ansicht nur unter Rückgriff auf unvereinheitlichtes nationales Recht gelöst werden können. ${ }^{194}$ Bezüglich anderer ist die Beurteilung dagegen noch im Fluss, wie sich am Beispiel der Aufrechnung zeigt: So hat sich der BGH, nachdem er lange in Übereinstimmung mit der überwiegenden Auffassung in anderen Vertragsstaaten $^{195}$ von der Anwendbarkeit nationalen Rechts ausgegangen war, jüngst für eine autonome Lückenfüllung durch übereinkommensimmanente Grundsätze ausgesprochen, soweit die Aufrechnung von Forderungen aus

189 Art. 6(2) Agency Convention (oben Fn. 77); Art. 4(2) UNIDROIT Factoring Convention und Art. 6(2) UNIDROIT Leasing Convention (oben Fn. 78); Art. 5(2) Übereinkommen von Kapstadt (oben Fn.6); Art. 7(2) UN Assignment Convention (oben Fn. 78); Art. 5(2) UN Electronic Communications Convention (oben Fn. 77).

${ }_{190}$ BGH 31.10.2001 - VIII ZR 60/01, BGHZ 149, 113, 118; zustimmend Schlechtriem/ Schwenzer/Ferrari (Fn. 45) Art. 7 Rn. 54; Staudinger/Magnus (Fn. 83) Art. 7 CISG Rn. 48.

191 Schlechtriem/Schroeter, Int. UN-Kaufrecht (Fn. 29) Rn. 153.

192 Schlechtriem/Schwenzer/Schwenzer/Hachem (Fn. 79) Art. 7 Rn. 36; wohl a. A. Kröll/ Mistelis/Perales Viscasillas/Perales Viscasillas (Fn. 76) Art. 7 Rn.61; ähnlich auch Philipp K. Wagner, in: Brunner, UN-Kaufrecht - CISG ${ }^{2}$ (2014) Art. 7 Rn. 10.

${ }_{193}$ Vgl. auch Veneziano, Unif. L. Rev. 2010, 137, $141 \mathrm{f}$.

194 Statt vieler Milena Djordjevic, in: Kröll/Mistelis/Perales Viscasillas, CISG (Fn. 76) Art. 4 Rn. 18, 46 m.w.Nachw. (Manches spricht dafür, dass es sich hierbei um „externe“ und nicht ,interne“ Übereinkommenslücken handelt.)

${ }^{195}$ Schlechtriem/Schwenzer/Ferrari (Fn. 45) Art. 4 Rn. 39 mit zahlreichen Nachw.

\section{Digitaler Sonderdruck des Autors mit Genehmigung des Verlages}


demselben CISG-Vertrag in Rede steht. ${ }^{196}$ Dem UN-Kaufrecht zugrunde liegende, allgemeine Grundsätze lassen sich auch für den Umgang mit aufschiebenden und auflösenden Bedingungen in Kaufverträgen oder hierauf bezogenen Parteierklärungen identifizieren. ${ }^{197}$ Nicht endgültig geklärt ist die Bestimmung der Zinshöhe, die von den Übereinkommensverfassern in Art. 78 CISG bewusst offen gelassen wurde: Während die internationale Gerichtspraxis und Literatur hierzu vorwiegend auf nationales Recht rekurriert, ${ }^{198}$ wird in der Wissenschaft teilweise für eine übereinkommensautonome Lückenfüllung eingetreten. ${ }^{199}$

\section{Einheitskaufrecht in der Schiedsgerichtsbarkeit}

Gesondert zu erwähnen ist schließlich die Anwendung des Einheitskaufrechts durch Schiedsgerichte. Mit Blick auf ihre Bedeutung wird verbreitet angenommen, dass sie unter dem UN-Kaufrecht den statistischen Regelfall darstellen dürfte ${ }^{200}$ - eine ausweislich anekdotischer Indizien wohl zutreffende Annahme, die empirisch freilich nicht sicher zu belegen ist. Vor diesem Hintergrund ist es bedauerlich, ${ }^{201}$ dass nur ein schmaler Ausschnitt der zum UN-Kaufrecht ergangenen Schiedssprüche veröffentlicht wird; Schätzungen gehen von weniger als $5 \%$ aus. ${ }^{202}$ Das hauptsächliche Anschauungsmaterial zur Praxis des Einheitskaufrechts bleibt damit vertraulich und für die Rechtsanwendungsöffentlichkeit unzugänglich, weshalb es auch nicht in den internationalen wissenschaftlichen Dialog ${ }^{203}$ eingehen kann. Die Leitfunktion für diesen Dialog wie für das Einheitlichkeitsstreben insgesamt verbleibt daher bei der veröffentlichten Gerichtspraxis zum Einheitskaufrecht, und zwar auch für Zwecke der schiedsgerichtlichen Anwendungspraxis selbst, weil der Schleier der Vertraulichkeit auch innerhalb der Schiedsgerichtsbarkeit CISG-Interpretationen durch andere Handelsschiedsgerichte als Informationsquelle ausschließt.

${ }^{196}$ BGH 24.9.2014 - VIII ZR 394/12, BGHZ 202, 258 Tz. 55 ff.; so auch Christiana Fountoulakis, in: Schlechtriem/Schwenzer, Kommentar (Fn. 45) Art.81 Rn. 21 f. Noch weitergehend Staudinger/Magnus (Fn. 83) Art. 4 CISG Rn. 47.

197 Ulrich G. Schroeter, Bedingte Parteierklärungen und Vertragsbindungen unter dem UN-Kaufrecht (CISG), in: FS Magnus (2014) 301, $304 \mathrm{ff}$.

198 Statt vieler Peter Huber, in: Münchener Kommentar zum BGB 6 (2012) Art. 78 CISG Rn. 14f. (m. Nachw. zur Rspr.); Schlechtriem/Schroeter, Int. UN-Kaufrecht (Fn. 29) Rn. 753 ff.

199 Siehe CISG-AC Opinion Nr. 14 (Rapporteur: Atamer), IHR 2014, $204 \mathrm{ff}$.

200 Loukas Mistelis, CISG and Arbitration, in: CISG Methodology (Fn. 81) 375, 387f.; André Janssen/Matthias Spilker, The Application of the CISG in the World of International Commercial Arbitration, RabelsZ 77 (2013) 131, 134; Schwenzer, IHR 2010, 45, 54.

201 Honsell/Melis (Fn. 103) Art. 7 Rn. 8.

202 Mistelis, CISG and Arbitration (Fn. 200) 387; ders., in Kröll/Mistelis/Perales Viscasillas, CISG (Fn. 76) Art. 1 Rn. 18

203 Oben V.2. b) (4).

Schwerpunkt: Stand und Perspektiven des Einheitsrechts

\section{Digitaler Sonderdruck des Autors mit Genehmigung des Verlages}




\section{Modellfunktion des UN-Kaufrechts}

Zur internationalen Privatrechtsvereinheitlichung hat das UN-Kaufrecht des Weiteren dadurch beigetragen, dass seine Regelungen bei der Schaffung anderer einheitsrechtlicher, regionaler oder nationaler Rechtsakte als Vorbild gedient haben. ${ }^{204}$ Diese Modellfunktion, die im Übereinkommen selbst nicht angelegt ist und seinen Verfassern wohl auch nicht unmittelbar vor Augen stand, wird gleichsam von außen an das Einheitskaufrecht herangetragen, indem sich sonstige Rechtsetzer an seinen rechtsvergleichend erarbeiteten und international anerkannten Vorschriften orientieren; sie hat in den letzten Jahrzehnten eine erhebliche Bedeutung erlangt.

\section{Modell für anderes Einheitsrecht}

Aus einheitsrechtlicher Perspektive ist primär von Interesse, inwiefern das UN-Kaufrecht zum Modell für andere einheitsrechtliche Regelwerke gedient hat. Eine solche intra-einheitsrechtliche Vorbildfunktion ist in der Tat unübersehbar, und zwar ohne Ansehen der im Einzelnen aktiven Rechtsvereinheitlichungsorganisation: So hat das UN-Kaufrecht nicht nur Vorschriften in zahlreichen späteren UNCITRAL-Übereinkommen ${ }^{205}$ inspiriert, sondern gleichermaßen Übereinkommen unter der Ägide UNIDROITs $^{206}$ und der Haager Konferenz für IPR. ${ }^{207}$ Da diese Übereinkommen jeweils andere Sachmaterien betrafen als das UN-Kaufrecht, kamen hierbei allerdings weniger den vertragsschluss- und kaufrechtsbezogenen Vorschriften in seinen Teilen II und III, sondern vor allem den allgemeinen Bestimmungen in Teil I (Art. 1-13 CISG) ${ }^{208}$ und den Schlussklauseln in Teil IV des UN-Kaufrechts (Art. 89-101 CISG) Modellfunktion zu. Diese setzen hinsichtlich ihres Regelungsgegenstandes (und ungeachtet gelegentlicher Abweichungen ${ }^{209}$ ) mittlerweile den globalen Standard und stellen damit gleichsam ein Einheitsrecht des Einheitsrechts dar.

204 Schlechtriem/Schroeter, Int. UN-Kaufrecht (Fn. 29) Rn. $18 \mathrm{ff}$.

205 So statt mancher etwa das UN-Übereinkommen über den elektronischen Geschäftsverkehr von 2005 (oben Fn. 77).

206 Etwa die Agency Convention (oben Fn. 77), deren Präambel ausdrücklich auf das UN-Kaufrecht Bezug nimmt.

207 Namentlich das Haager IPR-Übereinkommen von 1986 (oben Fn. 94); dazu Arthur Taylor von Mehren, Explanatory Report on the 1986 Hague Sales Convention (1987) 17: „Throughout the various stages of discussion and drafting, the greatest influence on the language of the draft Convention was a Convention dealing with substantive rules for international sales of goods [the CISG] [...]".

208 Zur Modellfunktion der Anwendungsvoraussetzungen in Art. 1 CISG Goode, Reflections (Fn. 39) $15 \mathrm{f}$.

209 Siehe zu solchen im Zusammenhang mit der Vorbildfunktion von Art. 7(1) und (2) CISG bereits oben V.2. a) und V.4.

Schwerpunkt: Stand und Perspektiven des Einheitsrechts

\section{Digitaler Sonderdruck des Autors mit Genehmigung des Verlages}


Noch folgenreicher dürfte der Einfluss des UN-Kaufrechts auf die Ausgestaltung nationaler und regionaler Regelwerke zum Vertragsrecht gewesen sein; Schlechtriem hat diese Modellfunktion sogar als langfristig vielleicht bedeutendsten Teil der Erfolgsgeschichte des Einheitskaufrechts ${ }^{210}$ beschrieben. Beispiele seiner Vorbildfunktion im Rahmen nationaler Reformen sind vielfältig und reichen vom chinesischen Vertragsrecht von 1999 über das russische Vertragsrecht und die Kaufrechte nordischer Staaten (Finnland, Norwegen, Schweden) bis zu den Vertragsrechten Estlands und Sloweniens; ${ }^{211}$ in Deutschland wurde die Schuldrechtsmodernisierung von 2001 maßgeblich durch das UN-Kaufrecht beeinflusst. ${ }^{212}$ Auf Ebene regionaler Rechtsangleichung ist insbesondere die Verbrauchsgüterkauf-Richtlinie der EG zu nennen, die einmal als „Adaption des CISG auf Verbraucherniveau“ ${ }^{213}$ charakterisiert worden ist, aber auch das Kaufrecht der westafrikanischen Staaten in der Organisation zur Harmonisierung des Wirtschaftsrechts in Afrika (OHADA). ${ }^{214}$ Übernahmen dieses Typs erstrecken die Sachlösungen des UN-Kaufrechts auch auf rein innerstaatliche Verträge und beweisen damit, dass sie auch hierfür taugen, obwohl das Übereinkommen in manchen Punkten spezifisch mit Blick auf den internationalen Handel ausgestaltet wurde. Insbesondere für kleinere Jurisdiktionen bieten sie den zusätzlichen Vorteil, dass dadurch auch die umfangreiche Rechtsprechung und Literatur zum UN-Kaufrecht aus zahlreichen Ländern als Erkenntnisquelle zur Verfügung steht - ein Bestand an Interpretationsmaterial, der bei Gesetzen mit rein nationalem Hintergrund typischerweise unerreichbar ist. ${ }^{215}$ Freilich sind entsprechende interpretative Wechselwirkungen von vornherein gleich einer Einbahnstraße beschränkt, weil der

${ }^{210}$ Peter Schlechtriem, 10 Jahre CISG - Der Einfluß des UN-Kaufrechts auf die Entwicklung des deutschen und des internationalen Schuldrechts, IHR 2001, 12.

${ }^{211}$ Siehe näher Franco Ferrari, General Report, in: The CISG and its Impact on National Legal Systems, hrsg. von dems. (2008) 474, 476ff.; Schlechtriem/Schwenzer/Schroeter (Fn. 182) Vor Art. 14-24 Rn. 48; jeweils m.w.Nachw.

212 Deutscher Bundestag, Entwurf eines Gesetzes zur Modernisierung des Schuldrechts, BT-Drucks. 14/6040 vom 14.5.2001, S. 86, 89; Abschlußbericht der Kommission zur Überarbeitung des Schuldrechts, hrsg. vom Bundesminister der Justiz (1992) 19f.; Reinhard Schubert, Der Einfluß des Einheitskaufrechts auf die Schuldrechtsreform in der Bundesrepublik Deutschland, in: Einheitliches Kaufrecht und nationales Obligationenrecht (Fn. 42) $415 \mathrm{ff}$.

${ }^{213}$ Hans-W. Micklitz, Ein einheitliches Kaufrecht für Verbraucher in der EG?, EuZW 1997, 229,230

214 Ulrich G. Schroeter, Das einheitliche Kaufrecht der afrikanischen OHADA-Staaten im Vergleich zum UN-Kaufrecht, Recht in Afrika (2001) $163 \mathrm{ff}$.

${ }^{215}$ Vgl. etwa Elisabeth Berger, Rezeption im liechtensteinischen Privatrecht unter besonderer Berücksichtigung des $\mathrm{ABGB}^{2}$ (2011) 1, 236. 
Auslegung des UN-Kaufrechts im Lichte nationalen Rechts der internationale Charakter des Einheitskaufrechts (Art. 7(1) CISG) entgegensteht. ${ }^{216}$

\section{Weiterentwicklung und Ergänzung des UN-Kaufrechts}

Die Zukunft des Einheitskaufrechts wirft zudem die Frage auf, ob und wie das vor nunmehr über drei Jahrzehnten angenommene UN-Kaufrecht weiterentwickelt ${ }^{217}$ und bzw. oder durch weiteres Einheitsrecht ergänzt ${ }^{218}$ werden kann und soll.

\section{Weiterentwicklung}

Die vorgebliche Gefahr einer „Versteinerung“ internationalen Einheitsrechts gehört zu den Kritikpunkten, die schon seit jeher gegen die Rechtsvereinheitlichung vorgetragen worden sind. ${ }^{219}$ Angesichts des zunehmenden Alters des Übereinkommenstextes liegt es nahe, dass Möglichkeiten zur Fortentwicklung des UN-Kaufrechts in Zukunft immer intensiver erörtert werden dürften.

\section{a) Revision des Übereinkommenstextes?}

Eine Weiterentwicklung des geltenden Einheitskaufrechts durch Neufassung des UN-Kaufrechts erscheint dabei weder als realistisch machbar noch als sinnvoll. Zwar dürfte ihre Durchführbarkeit nicht schon daran scheitern, dass das UN-Kaufrecht - anders als andere Übereinkommen ${ }^{220}$ - keine ausdrückliche Revisionsklausel ${ }^{221}$ aufweist, weil die Relationsnorm ${ }^{222}$ des Art. 90 CISG auch den Vorrang eines Nachfolgeübereinkommens sichern könnte. ${ }^{223}$ Das entscheidende Hindernis liegt jedoch in der erforderlichen Ratifikation des neuen Übereinkommens, ${ }^{224}$ die angesichts der augenblicklich 85 Vertragsstaa-

216 Schlechtriem/Schwenzer/Schroeter (Fn. 182) Vor Art. 14-24 Rn. 52.

217 Dazu sogleich unter VII.1.

218 Unter VII.2.

219 Basedow, Depositivierungstendenzen (Fn. 99) 791; vorsichtig auch Kötz, RabelsZ 50 (1986) 1, 12.

220 So etwa Art. 49 CMR; Art. XIV Convention relating to a Uniform Law on the International Sale of Goods (oben Fn. 17); Art. 23 f. UN Convention on the Liability of Operators of Transport Terminals (oben Fn. 94).

$221 \mathrm{Zu}$ diesen auch Basedow, RabelsZ 81 (2017) 1, 28 (in diesem Heft).

222 Dazu noch unter VIII.1.

223 Malcolm Evans, in: Bianca/Bonell, Commentary on the International Sales Law (1987) Art. 90 Anm. 2.1; Honnold/Flechtner, Uniform Law (Fn. 82) Rn. 463; Staudinger/Magnus (Fn. 83) Art. 90 CISG Rn. 1; a.A. Enderlein/Maskow/Strohbach, Int. Kaufrecht (Fn. 4) Art. 90 Anm. 3.

${ }^{224}$ IECL/David (Fn. 51) Anm. 318. 
ten des UN-Kaufrechts kaum flächendeckend erreichbar scheint oder jedenfalls durch eine Jahrzehnte währende Parallelgeltung beider Einheitsrechtsfassungen erkauft würde. (Das Schicksal des deutlich weniger verbreiteten UN-Verjährungsübereinkommens ${ }^{225}$ legt hiervon beredtes Zeugnis ab.) Angesichts dieses einheitsbeeinträchtigenden Effekts kann eine Revision des UN-Kaufrechts nur die ultima ratio unter den Weiterentwicklungsmöglichkeiten sein, die nur dann in Betracht gezogen werden sollte, wenn tiefgreifende und zugleich flächendeckende Schwächen seiner inhaltlichen Lösungen offenkundig werden. Solche sind bislang nicht ersichtlich.

b) Primat judikativer Weiterentwicklung

Die Zukunft gehört daher der Fortentwicklung des Einheitskaufrechts auf Grundlage von Art.7(1) und (2) CISG, mittels derer die Rechtsprechung mit Unterstützung der Wissenschaft von den Übereinkommensverfassern nicht vorhergesehenen technischen und wirtschaftlichen Entwicklungen Rechnung zu tragen vermag. ${ }^{226}$ Wo erforderlich, ist dabei eine dynamische Auslegung des UN-Kaufrechts angebracht; zudem mag die progressive Ermittlung und Anwendung allgemeiner Grundsätze i.S.d. Art.7(2) CISG eine einheitsrechtsautonome Lückenfüllung zunehmend auch dort erlauben, wo anfänglich noch auf nationales Recht zurückgegriffen wurde. In jüngerer Zeit entwickelte Ansätze zum Umgang mit allgemeinen schuldrechtlichen Instituten wie der Aufrechnung oder auflösenden bzw. aufschiebenden Bedingungen ${ }^{227}$ bieten Beispiele hierfür. Das häufig verwandte Bild der drohenden „Versteinerung“ eines alternden Übereinkommens erscheint vor diesem Hintergrund nicht als treffend - Einheitsrecht gleicht vielmehr einem lebenden Organismus, der sich durch eine judikative Weiterentwicklung veränderten Umständen anpassen kann.

\section{Ergänzung durch weiteres Einheitsrecht}

Angesichts des beschränkten sachlichen Anwendungsbereichs des Einheitskaufrechts ist allerdings auch seine Ergänzung durch weiteres Einheitsrecht erwägenswert, die in formeller Hinsicht durch flankierende Konventionen $^{228}$ oder auch durch Modellgesetze oder soft law erfolgen könnte. Ein zentrales Problem ist hier die drohende Kleinteiligkeit des entstehenden Einheitsrechts, welche die Komplexität der Rechtsanwendung signifikant

225 Oben Fn. 30.

${ }^{226}$ Schlechtriem/Schwenzer/Schwenzer/Hachem (Fn. 79) Art. 7 Rn. 5. Vgl. zur Rechtsfortbildung im Einheitsrecht auch Kropholler, Int. Einheitsrecht (Fn. 8) 292 ff.

227 Siehe dazu bereits oben V.4.

${ }^{228}$ Enderlein/Maskow/Strohbach, Int. Kaufrecht (Fn. 4) 30. 
erhöht. Es erscheint daher vorzugswürdig, ergänzendes Einheitsrecht inhaltlich breit anzulegen ${ }^{229}$ und wesentliche Bereiche des allgemeinen Vertragsrechts darin abzudecken - auch um den Preis längerer Vorarbeiten und gegebenenfalls notwendiger Vorbehaltsmöglichkeiten. ${ }^{230}$ Wo lediglich schmale Teilbereiche vereinheitlicht werden, ${ }^{231}$ steht dem Vorteil zusätzlicher Rechtseinheit dagegen der Nachteil zusätzlicher Anwendungskomplexität gegenüber. Letztere kann zwar dadurch reduziert werden, dass die Anwendungsvoraussetzungen des neuen Einheitsrechtsakts parallel zu denjenigen des UN-Kaufrechts ausgestaltet werden, wie dies etwa beim UNVerjährungsübereinkommen, ${ }^{232}$ jüngst beim UN-Übereinkommen über den elektronischen Geschäftsverkehr und im Ansatz auch beim Haager IPR-Übereinkommen von $1986^{233}$ praktiziert wurde; ein vollkommener Gleichlauf entsteht hierdurch allein gleichwohl nicht, weil dazu auch die Vertragsstaatenbestände übereinstimmen müssten.

\section{Koordination und Konfliktauflösung innerhalb des kaufrechtsbezogenen Einheitsrechts}

Die bestehenden Einheitsrechtsakte mit Bezug zu grenzüberschreitenden Kaufverträgen wurden von unterschiedlichen Organisationen mit unterschiedlichen Anwendungsvoraussetzungen und gelegentlich auch unterschiedlicher Zielsetzung erarbeitet, können aber von ein und demselben Rechtsanwender auf ein und denselben Kaufvertrag anzuwenden sein. Dieser Umstand macht eine Koordination und gegebenenfalls Konfliktauflösung innerhalb des kaufrechtsbezogenen Einheitsrechts erforderlich. Da zu erwarten steht, dass die Schaffung zumindest kaufrechtsnahen Einheitsrechts auch künftig nicht abreißen wird, handelt es sich hierbei um einen Fragenkreis, dem für die Zukunft des Einheitskaufrechts große Bedeutung zukommt.

\section{Internationale Einheitsrechtsakte}

Sofern eine solche Koordination nicht bereits - wie wünschenswert ${ }^{234}$ im Zuge der Schaffung neuer Einheitsrechtsakte erfolgt ist, indem deren

229 Kropholler, Int. Einheitsrecht (Fn. 8) $227 \mathrm{f}$.

${ }^{230}$ Siehe zur potentiell rechtseinheitlichkeitsfördernden Wirkung von Vorbehalten schon oben III.2.

${ }^{231}$ Ein Beispiel ist das UN-Übereinkommen über den elektronischen Geschäftsverkehr von 2005 (oben Fn. 77).

232 Oben Fn. 30 (dort bewirkt durch das Änderungsprotokoll von 1980).

233 Oben Fn. 94; dazu von Mehren, Explanatory Report (Fn. 207) 17.

234 Goode, Reflections (Fn. 39) 7, 9; Kropholler, Int. Einheitsrecht (Fn. 8) 43f. Dieses Desiderat ist nicht neu; vgl. schon UNCITRAL Yearbook I (1968-1970) 98 Nr. 27.

Schwerpunkt: Stand und Perspektiven des Einheitsrechts

\section{Digitaler Sonderdruck des Autors mit Genehmigung des Verlages}


Verhältnis zu bereits vorhandenem Einheitsrecht bedacht und klar geregelt wurde, ${ }^{235}$ muss mit der entstandenen Unübersichtlichkeit ${ }^{236}$ umgegangen werden. Wertvolle Hilfe könnte hier schon ein unverbindlicher Leitfaden leisten, in dem das Zusammenspiel der diversen kaufrechtsnahen Einheitsrechtsakte dem Rechtsanwender leicht verständlich erläutert wird. Stehen mögliche Konkurrenz- und gegebenenfalls Konfliktlagen zwischen mehreren Rechtsakten im Raum, so ist deren Auflösung zuallererst die Aufgabe expliziter Relationsnormen, ${ }^{237}$ die das Verhältnis eines Einheitsrechtsakts zu konkurrierenden Rechtsakten regeln. Da viele Relationsnormen jedoch ihrerseits auslegungsbedürftig sind und zudem das Zusammenspiel mehrerer solcher Vorschriften bedacht werden muss, ist hier manches unsicher. ${ }^{238}$ Hinzu kommt erstens, dass manche scheinbar geringfügige, aber für die Praxis sehr relevante Überschneidungen des UN-Kaufrechts mit Einheitsrechtsakten zum Verfahrensrecht (namentlich zur Einigung auf und der Formbedürftigkeit von Gerichtsstands- oder Schiedsklauseln in CISG-Verträgen ${ }^{239}$ ) erst in jüngerer Zeit erkannt worden sind und bei Abfassung der bestehenden Relationsnormen nicht bedacht wurden. Und zweitens ist unverändert umstritten, ob materiellem Einheitsrecht stets der Vorrang vor Einheitskollisionsrecht gebührt (,ohne Rechtskollisionen kein Kollisionsrecht" ${ }^{240}$ - eine Frage, die sich etwa bei paralleler Anwendbarkeit von UN-Kaufrecht und Haager IPR-Übereinkommen von $1955^{241}$ stellt. Richtigerweise wird man anzunehmen haben, dass es an einer Grundlage für eine generelle Rechtsanwendungsregel des beschriebenen Inhalts fehlt, ${ }^{242}$ zumal der Anwendungsbereich kollisions- wie materiell-rechtlicher Einheitsrechtsakte ja ganz unterschiedlich weit oder eng geschnitten sein kann; ${ }^{243}$ auch in einer solchen Konkurrenzlage kommt es daher vorrangig auf Relationsnormen an.

${ }^{235}$ So etwa in Art. 99(3)-(6) CISG das Verhältnis des UN-Kaufrecht zum Haager Kaufrecht von 1964 .

${ }^{236}$ Kötz, RabelsZ 50 (1986) 1, 5.

237 Zum Begriff Schroeter, UN-Kaufrecht (Fn. 136) \& 7 Rn. 27 ff.

238 Vgl. dazu Schroeter, UN-Kaufrecht (Fn. 136) \$7 Rn. 35 ff., \$ 9 Rn. $71 \mathrm{ff}$.

239 Dazu jüngst Ulrich G. Schroeter, in: Schlechtriem/Schwenzer (Fn. 79) Intro to Arts. 14-24 CISG Rn. 16 ff.

${ }^{240}$ So griffig Konrad Zweigert/Ulrich Drobnig, Einheitliches Kaufgesetz und Internationales Privatrecht, RabelsZ 29 (1965) 146, 147 ff.; ebenso statt mancher Trib. Forli 11.12.2008 (Mitias v. Solidea S.r.l.); Schlechtriem/Schwenzer/Ferrari (Fn. 45) Vor Art. 1-6 CISG Rn. 34 m.w.Nachw.

241 Oben Fn. 12.

242 Schroeter, UN-Kaufrecht (Fn. 136) \$14 Rn. 89 ff.

${ }^{243}$ Beispiele für Einheitsrechtsakte, die ,jeweils nur Ausschnitte und Bruchstücke“ des Vertrags- oder Deliktsrechts regeln, nennt Kötz, RabelsZ 50 (1986) 1, 3. 
2. UN-Kaufrecht und regionale Rechtsvereinheitlichung (insbesondere in der EU)

Koordinations- und Konfliktlösungsaufgaben wirft in jüngerer Zeit auch das Verhältnis des Einheitskaufrechts zu Projekten der regionalen Rechtsvereinheitlichung ${ }^{244}$ auf; sie drohen in Zukunft noch an Bedeutung zu gewinnen. Der Status quo ist dabei dadurch gekennzeichnet, dass das UN-Kaufrecht angesichts seines Ratifikationsstandes ${ }^{245}$ - und ungeachtet seiner Eigenschaft als globales Einheitsrecht, das auf weltweite ${ }^{246}$ Rechtseinheit zielt - auch innerhalb regionaler Organisationen und Staatenzusammenschlüsse bereits weitgehende Rechtseinheit für grenzüberschreitende Handelskäufe schafft. Dies gilt namentlich für das Nordamerikanische Freihandelsabkommen (NAFTA), dessen drei Mitgliedstaaten sämtlich das UN-Kaufrecht in Kraft gesetzt haben, aber auch für die EU, weil 24 der 28 augenblicklichen EU-Staaten dem Übereinkommen angehören. Diese Lage ist freilich einer unterschiedlichen Beurteilung zugänglich, die davon abhängen kann, ob sie aus der Perspektive eines handeltreibenden Unternehmens oder aber einer regionalen Organisation mit Rechtsvereinheitlichungskompetenz vorgenommen wird: Aus erstgenannter Perspektive ist es positiv einzuschätzen, wenn einheitliches Kaufrecht nicht nur innerhalb regionaler Zusammenschlüsse, sondern über deren Grenzen hinaus identisch gilt, weil auch der Warenhandel nicht an regionalen Grenzen haltmacht - es empfiehlt sich daher ein globales Recht für globale Wirtschaftsströme. In den Augen derjenigen Organe, die für eine regionale Rechtsvereinheitlichung zuständig sind, mag das UN-Kaufrecht dagegen wie ein einheitsrechtliches „Kuckucksei“ erscheinen, das in Gestalt des grenzüberschreitenden Handelskaufvertrags zudem den aus wirtschaftlicher (Binnenmarkt-)Sicht zentralen Vereinheitlichungsgegenstand besetzt und damit gleichsam quer zu regionalen Einheitsrechtsprojekten liegt. Damit übereinstimmend ist die Haltung der EU-Kommission zum UN-Kaufrecht stets skeptisch-distanziert gewesen. ${ }^{247}$

${ }^{244}$ Dazu umfassend Schroeter, UN-Kaufrecht (Fn. 136).

245 Oben III.1.

246 Bianca/Bonell/Bonell (Fn. 83) Art. 7 Anm. 2.2.2.

${ }^{247}$ Vgl. etwa Grünbuch der Kommission: Optionen für die Einführung eines Europäischen Vertragsrechts für Verbraucher und Unternehmen vom 1.7.2010, KOM(2010) 348 endg., 3 f., 9 f.; Vorschlag für eine Verordnung des Europäischen Parlaments und des Rats für ein Gemeinsames Europäisches Kaufrecht vom 11.10.2011, KOM(2011)635 endg., 6; Mitteilung der Kommission an das Europäische Parlament, den Rat, den Europäischen Wirtschaftsund Sozialausschuss und den Ausschuss der Regionen: Ein Gemeinsames Europäisches Kaufrecht zur Erleichterung grenzübergreifender Geschäfte im Binnenmarkt vom 11.10.2011, $\operatorname{KOM}(2011) 636$ endg., 6. Siehe dazu auch Ulrich G. Schroeter, Der digitale Binnenmarkt für Europa und das UN-Kaufrecht, ZVglRWiss 115 (2016) 270, $281 \mathrm{ff}$.

Schwerpunkt: Stand und Perspektiven des Einheitsrechts

\section{Digitaler Sonderdruck des Autors mit Genehmigung des Verlages}


Regionale Organisationen haben vor diesem Hintergrund zunächst zu prüfen, ob und inwieweit ihnen trotz der durch das Einheitskaufrecht bereits bewirkten Rechtseinheit noch eine Kompetenz für regionale, kaufrechtliche Vereinheitlichungsmaßnahmen bleibt. In Kategorien des EU-Rechts ist damit die Erforderlichkeit eines Tätigwerdens der EU (Art. 5(4) EUV, Art. 26(1), 81(2), 352(1) AEUV) angesprochen, an der es im Anwendungsbereich des UN-Kaufrechts fehlen dürfte, weil die insbesondere zur Gewährleistung des Funktionierens des Binnenmarktes angestrebte Rechtseinheit durch das Übereinkommen eben schon verwirklicht ist. ${ }^{248}$ Daran ändert auch der Umstand nichts, dass das UN-Kaufrecht keiner Auslegungskompetenz des $\mathrm{EuGH}^{249}$ unterliegt, ${ }^{250}$ weil durch dieses Argument andernfalls eine allumfassende EU-Kompetenz eröffnet würde, die mit dem Prinzip der begrenzten Einzelermächtigung (Art. 5 EUV) unvereinbar ist. Sinnvoller wäre es daher, wenn die EU-Kommission versuchen würde, die noch verbleibenden Nichtvertragsstaaten innerhalb der EU (Irland, Malta, Portugal und das Vereinigte Königreich ${ }^{251}$ ) zum Beitritt zum UN-Kaufrecht zu bewegen, um dadurch zugleich europäische wie globale Rechtseinheit zu schaffen. ${ }^{252}$

Die Schaffung regionalen Einheitsrechts für kaufrechtsnahe Materien empfiehlt sich demgegenüber nur dort, wo dieses aufgrund regionalspezifischer Besonderheiten einen Mehrwert gegenüber globalem Einheitsrecht verspricht oder wo Letzteres aus anderem Grund nicht erreichbar scheint. Die im Anwendungsbereich des UN-Kaufrechts bereits bestehende Rechtseinheit sollte jedenfalls dadurch gewahrt werden, dass das regionale Recht dem Übereinkommen durch eine klar gefasste Relationsnorm Anwendungsvorrang einräumt.

\section{Zusammenfassung}

Das internationale Einheitskaufrecht umfasst als Teilbereich des Einheitsprivatrechts eine Reihe kollisions- wie materiellrechtlicher Übereinkommen. Nachdem zunächst das Haager IPR-Übereinkommen von 1955 und sodann das Haager Einheitliche Kaufrecht von 1964 eine gewisse Rechtsein-

248 Jürgen Basedow, Die Europäische Gemeinschaft als Partei von Übereinkommen des einheitlichen Privatrechts, in: FS Peter Schlechtriem (2003) 165, 168; Stefan Leible, Die Mitteilung der Kommission zum Europäischen Vertragsrecht - Startschuss für ein Europäisches Vertragsrecht, EWS 2001, 471, 473; Schroeter, UN-Kaufrecht (Fn. 136) \$16 Rn. 9; ders., ZVglRWiss 115 (2016) 270, $284 \mathrm{f}$.

${ }^{249}$ Oben V.2. b) (1).

${ }^{250}$ So aber Karl Kreuzer, Die Europäisierung des Internationalen Privatrechts - Vorgaben des Gemeinschaftsrechts, in: Gemeinsames Privatrecht in der Europäischen Gemeinschaft, hrsg. von Peter-Christian Müller-Graff (1993) 373, 432.

251 Zum Vereinigten Königreich bereits oben II.2. und III.1.

252 Castellani, Vindobona J. of Int'l Commercial Law \& Arbitration 13 (2009) 241, 242.

Schwerpunkt: Stand und Perspektiven des Einheitsrechts

\section{Digitaler Sonderdruck des Autors mit Genehmigung des Verlages}


heit erbracht hatten, die jedoch auf einige westeuropäische Staaten beschränkt war, gelang UNCITRAL mit dem UN-Kaufrecht von 1980 (CISG) einer der größten Erfolge in der Vereinheitlichung des Privatrechts insgesamt.

Seine heute bereits über 80 Vertragsstaaten belegen dabei, dass das UN-Kaufrecht unter den Staaten der Welt weitgehende Akzeptanz erlangt hat. Unter den Vertragsstaaten finden sich sowohl fast alle im internationalen Handel bedeutenden Länder als auch Staaten aus allen Erdteilen. Künftig wird insbesondere die Ratifikation des Übereinkommens durch Entwicklungsländer aktiv zu fördern sein.

Demgegenüber ist die Akzeptanz des Einheitskaufrechts durch private Parteien empirisch kaum verlässlich zu messen. Vertragliche Ausschlüsse der Übereinkommensanwendung, die Art. 6 CISG zulässt, sind in der Praxis wohl seltener als gelegentlich vermutet, weil die Rechtsprechung hierzu eine klar gefasste Abrede verlangt und insbesondere eine nachweisbare Einigung beider Vertragsparteien nötig ist, an der es häufig fehlt. Problematisch ist, dass die Anwendung des Einheitskaufrechts überwiegend durch Schiedsgerichte erfolgen dürfte, deren Schiedssprüche aber in der Regel vertraulich bleiben.

In Zukunft wird vor allem das Bestreben um eine einheitliche Auslegung des UN-Kaufrechts im Vordergrund stehen. Dieses versucht Art. 7(1) CISG durch die Vorgabe von drei Auslegungszielen zu steuern, die in der Praxis bislang im Wesentlichen beachtet und durch eine einheitliche Übereinkommensinterpretation umgesetzt wurden; begrenzte Ausnahmen hiervon kommen aber vor. Als Herausforderung erweist sich dabei namentlich, dass Kaufverträge im internationalen Handel Alltagsverträge sind, sodass die Anwendung des UN-Kaufrechts nicht vorrangig durch spezialisierte Rechtsanwender erfolgt. Die Einheitlichkeit seiner Interpretation muss daher durch organisatorische Arrangements unterstützt und gefördert werden, wobei der sinnvollste Ansatz in einer grenzüberschreitenden Kooperation der Wissenschaft liegen dürfte, mittels derer die internationale Rechtsprechung zum Einheitskaufrecht geordnet und inländischen Rechtsanwendern zugänglich gemacht werden kann.

Zusätzlichen Einfluss hat das UN-Kaufrecht durch seine Modellfunktion erlangt, weil zahlreiche internationale und nationale Rechtsakte seinen Normen nachgebildet wurden. Demgegenüber erscheint seine formelle Revision durch Änderung seines Übereinkommenstextes weder naheliegend noch wünschenswert; die Weiterentwicklung des UN-Kaufrechts liegt vielmehr in den Händen von Rechtsprechung und Wissenschaft.

Die signifikante Anzahl an Einheitsrechtsakten im kaufrechtlichen oder -nahen Bereich erfordert künftig schließlich eine bessere Koordination der Einheitsrechtsetzung, in deren Rahmen die regionale Rechtsetzung (namentlich der EU) die Stellung des UN-Kaufrechts vorzugsweise durch Vorrangklauseln respektieren sollte. 


\section{Summary \\ Present and Future of Uniform Sales Law}

Uniform sales law forms a part of uniform private law that comprises a number of Conventions unifying either conflict-of-laws rules for sales or substantive sales law. The Hague Convention on the Law Applicable to International Sales of Goods (1955) and the Hague Uniform Sales Laws of 1964 achieved a certain legal uniformity for international sales contracts, but both were ratified by only a few Western European States. The UN (Vienna) Sales Convention of 1980 (CISG) has, in turn, developed into one of the greatest successes of uniform law-making in private law.

The currently more than 80 Contracting States are proof of the fact that the CISG has been accepted by the global community of States. Its Contracting States include most major international trading nations and at the same time countries from all regions of the world. In the upcoming years, the Sales Convention's ratification by further developing States should be actively encouraged.

By contrast, the extent to which the CISG has been accepted in commercial practice is very difficult to assess empirically. Much is to be said for the assumption that its contractual exclusion is significantly less common than sometimes alleged, given that the courts require a clearly expressed intention to exclude and that any exclusion needs to be agreed upon by both parties, which is often not the case. The assessment of the Sales Convention's practical importance is further complicated by its frequent application by arbitral tribunals, because the resulting arbitral awards usually remain confidential and thus inaccessible.

In the future, the quest for a uniform interpretation of the Sales Convention is likely to be the most important challenge. Article 7(1) CISG provides some guidance by imposing three interpretative goals that in practice have mostly been observed. They have resulted in a generally uniform interpretation, although limited areas of non-uniformity exist. A general challenge arises from sales contracts' nature as everyday contracts in international trade, resulting in the uniform sales law's frequent application by non-specialised lawyers. It is therefore necessary to enable and assist a uniform interpretation through appropriate organisational arrangements, with a cross-border cooperation among specialised academics as the most suitable solution, designed to evaluate and assess international CISG case law and make it available to uniform law users in every country.

The Sales Convention has furthermore contributed to legal uniformity through its use as a model for other international Conventions as well as for domestic and regional law reforms. By contrast, a future revision of the Convention's text seems neither desirable nor realistic, with its further development best being left to courts and legal academia.

Finally, the increasing number of uniform law acts for international sales calls for a better coordination between the various law-making organisations. In particular, regional uniform law (notably EU law) should respect the existing uniform sales law by explicitly granting priority to the CISG. 